\title{
Four-dimensional variational data assimilation for inverse modeling of atmospheric methane emissions: Analysis of SCIAMACHY observations
}

\author{
Jan Fokke Meirink, ${ }^{1,2}$ Peter Bergamaschi, ${ }^{3}$ Christian Frankenberg, ${ }^{4}$ \\ Monica T. S. d'Amelio, ${ }^{5}$ Edward J. Dlugokencky, ${ }^{6}$ Luciana V. Gatti, ${ }^{5}$ \\ Sander Houweling, ${ }^{1,4}$ John B. Miller, ${ }^{6}$ Thomas Röckmann, ${ }^{1}$ \\ M. Gabriella Villani, ${ }^{3}$ and Maarten C. Krol, ${ }^{1,4,7}$ \\ Received 20 December 2007; revised 16 April 2008; accepted 19 June 2008; published 4 September 2008.
}

[1] Recent observations from the Scanning Imaging Absorption Spectrometer for Atmospheric Chartography (SCIAMACHY) instrument aboard ENVISAT have brought new insights in the global distribution of atmospheric methane. In particular, the observations showed higher methane concentrations in the tropics than previously assumed. Here, we analyze the SCIAMACHY observations and their implications for emission estimates in detail using a four-dimensional variational (4D-Var) data assimilation system. We focus on the period September to November 2003 and on the South American continent, for which the satellite observations showed the largest deviations from model simulations. In this set-up the advantages of the 4D-Var approach and the zooming capability of the underlying TM5 atmospheric transport model are fully exploited. After application of a latitude-dependent bias correction to the SCIAMACHY observations, the assimilation system is able to accurately fit those observations, while retaining consistency with a network of surface methane measurements. The main emission increments resulting from the inversion are an increase in the tropics, a decrease in South Asia, and a decrease at northern hemispheric high latitudes. The SCIAMACHY observations yield considerable additional emission uncertainty reduction, particularly in the (sub-)tropical regions, which are poorly constrained by the surface network. For tropical South America, the inversion suggests more than a doubling of emissions compared to the a priori during the 3 months considered. Extensive sensitivity experiments, in which key assumptions of the inversion set-up are varied, show that this finding is robust. Independent airborne observations in the Amazon basin support the presence of considerable local methane sources. However, these observations also indicate that emissions from eastern South America may be smaller than estimated from SCIAMACHY observations. In this respect it must be realized that the bias correction applied to the satellite observations does not take into account potential regional systematic errors, which - if identified in the future - will lead to shifts in the overall distribution of emission estimates.

Citation: Meirink, J. F., et al. (2008), Four-dimensional variational data assimilation for inverse modeling of atmospheric methane emissions: Analysis of SCIAMACHY observations, J. Geophys. Res., 113, D17301, doi:10.1029/2007JD009740.

\footnotetext{
${ }^{1}$ Institute for Marine and Atmospheric Research Utrecht, University of Utrecht, Utrecht, Netherlands.

${ }^{2}$ Now at Climate Observations Department, Royal Netherlands Meteorological Institute (KNMI), De Bilt, Netherlands.

${ }^{3}$ European Commission Joint Research Centre, Institute for Environment and Sustainability, Ispra (VA), Italy.

${ }^{4}$ Netherlands Institute for Space Research (SRON), Utrecht, Netherlands.

${ }^{5}$ Instituto de Pesquisas Energéticas e Nucleares, São Paulo, Brazil.

${ }^{6}$ NOAA Earth System Research Laboratory, Boulder, Colorado, USA.

${ }^{7}$ Wageningen University and Research Centre, Wageningen, Netherlands.

Copyright 2008 by the American Geophysical Union. 0148-0227/08/2007JD009740
}

\section{Introduction}

[2] Since pre-industrial times, methane concentrations in the atmosphere have more than doubled [e.g., Etheridge et al., 1992]. This is important because methane is a strong greenhouse gas and because it influences the oxidizing capacity of the atmosphere. Despite considerable observational and modeling efforts, the magnitude of the various methane sources and their spatial distribution remain poorly known. Improved knowledge on emissions is required to explain past trends and variability and to make predictions for the future evolution of methane concentrations. 
[3] A powerful tool to narrow uncertainties in existing bottom-up emission inventories is inverse modeling using atmospheric observations. Regarding methane, inverse modeling has so far almost exclusively been based on surface observations, both weekly flask samples at $\sim 50$ globally distributed remote sites [Hein et al., 1997; Houweling et al., 1999; Mikaloff Fletcher et al., 2004; Chen and Prinn, 2006; Bousquet et al., 2006] and quasicontinuous in-situ measurements at a number of European sites [Bergamaschi et al., 2005].

[4] Recently, satellite observations of atmospheric methane became available from the Scanning Imaging Absorption Spectrometer for Atmospheric Chartography (SCIAMACHY) instrument on board ESA's environmental satellite ENVISAT [Buchwitz et al., 2005; Frankenberg et al., 2005, 2006; Buchwitz et al., 2006]. These satellite observations enabled for the first time the global mapping of column-averaged atmospheric methane mixing ratios with sensitivity down to the surface. Frankenberg et al. [2005] found that in the tropics, a region that is poorly covered by the surface measurement network, $\mathrm{CH}_{4}$ concentrations observed by SCIAMACHY are higher than assumed previously. Frankenberg et al. [2006] presented a longer, two-year, SCIAMACHY $\mathrm{CH}_{4}$ data set, showing that the most pronounced tropical methane enhancements compared to model simulations occur in the months September to November. Bergamaschi et al. [2007] conducted synthesis inversions, constraining continental-scale emissions by these SCIAMACHY observations.

[5] The goal of this paper is to go a step further by using the four-dimensional variational (4D-Var) data assimilation system presented in Meirink et al. [2008] to assess the implications of SCIAMACHY observations for methane emission estimates. The main advantage of the 4D-Var system compared to the synthesis approach is that it can both handle large volumes of observations and optimize a large number of model parameters. This allows to optimize emissions on the model grid scale rather than over large regions, while at the same time the satellite observations can be assimilated at high spatial and temporal resolution, thus preserving information on synoptic scales contained in the observations. Statistics of differences between observations and optimized model simulations will be analyzed to give an indication of observation errors.

[6] Motivated by the results of previous analyses of SCIAMACHY observations mentioned above, inversions are conducted for September to November 2003 and with a special focus on the South American continent, using the zooming capability of the TM5 atmospheric transport model [Krol et al., 2005]. We investigate whether this zooming helps to optimally exploit spatial variability in the SCIAMACHY observations for constraining emission rates. A suite of sensitivity experiments are performed to assess the robustness of the results to key assumptions and settings in the inversion set-up. A comparison with independent airborne observations [Miller et al., 2007] is presented to validate the optimized model simulations and thus indirectly the SCIAMACHY observations.

[7] The paper is structured as follows. In section 2 the model, observations and inversion set-up are outlined. Results of the reference inversion are presented in section 3, and sensitivity experiments in section 4. A comparison of the inversion results with independent observations is performed in section 5. Finally, the main conclusions are summarized in section 6 .

\section{Method}

\subsection{Model}

[8] The 4D-Var implementation as well as the underlying atmospheric transport model TM5 and its adjoint have been extensively discussed in Meirink et al. [2008]. Here the main characteristics of our (inverse) modeling setup are summarized.

[9] The TM5 model is a global offline chemistry-transport model with two-way nested zooming capability [Krol et al., 2005]. We use the methane tracer version as described in Bergamaschi et al. [2007] in combination with its adjoint. The model is operated on a basic horizontal resolution of $6^{\circ} \times 4^{\circ}$ globally with the possibility to zoom to $1^{\circ} \times 1^{\circ}$ over regions of interest.

[10] 4D-Var is a variational data assimilation technique that iteratively minimizes a cost function $J$ as a function of a control vector $\mathbf{x}$ :

$$
J(\mathbf{x})=\frac{1}{2}\left(\mathbf{x}-\mathbf{x}^{b}\right)^{T} \mathbf{B}^{-1}\left(\mathbf{x}-\mathbf{x}^{b}\right)+\frac{1}{2}(\mathbf{H} \mathbf{x}-\mathbf{y})^{T} \mathbf{R}^{-1}(\mathbf{H} \mathbf{x}-\mathbf{y}) .
$$

This cost function measures the difference between a forward model simulation (operator $\mathbf{H}$ applied to the control vector) and observations $\mathbf{y}$ available during the assimilation time window (typically a month to a few years) and the deviation of the control vector from its background (also termed prior) estimate $\mathbf{x}^{b}$. Note that in equation (1) the time dimension in the operator $\mathbf{H}$ and in the observation vector $\mathbf{y}$ has not been denoted explicitly. In our case, the control vector can be written as $\mathbf{x}=\left(\mathbf{s}_{1}^{T}, \ldots, \mathbf{s}_{m}^{T}, \mathbf{c}^{T}, \mathbf{p}^{T}\right)^{T}$, where $\mathbf{s}_{i}$ are monthly-mean grid-based surface emissions for source category $i$ and $m$ is the number of source categories that are distinguished, $\mathbf{c}$ is the three-dimensional concentration field at the start of the assimilation window, and $\mathbf{p}$ contains any additional parameters, as specified in section 2.3. $\mathbf{R}$ and $\mathbf{B}$ are the error covariance matrices of $\mathbf{y}$ and $\mathbf{x}^{b}$, respectively. The background error covariance matrix $\mathbf{B}$ is split into spatial and temporal error correlation matrices as described in Meirink et al. [2008]. Spatial correlations are modeled as Gaussian functions of the distance between grid cells, with correlation lengths $L_{\mathbf{s}_{i}}$ for the various source categories and $L_{\mathbf{c}}$ for the initial concentration field. Temporal correlations are modeled as exponential functions of the time difference, with correlation time scales $\tau_{\mathbf{s}_{i}}$. Vertical correlations of errors in the initial concentration field have been determined with the National Meteorological Center (NMC) method as outlined in Meirink et al. [2006].

[11] The minimization procedure involves iterative calculations of the cost function and its gradient, using the forward and adjoint TM5 models, respectively. The actual minimization algorithm is the same as employed in the ECMWF 4D-Var system [Fisher and Courtier, 1995]. This method produces estimates of the leading eigenvalues and eigenvectors of the analysis (hereafter termed posterior) 


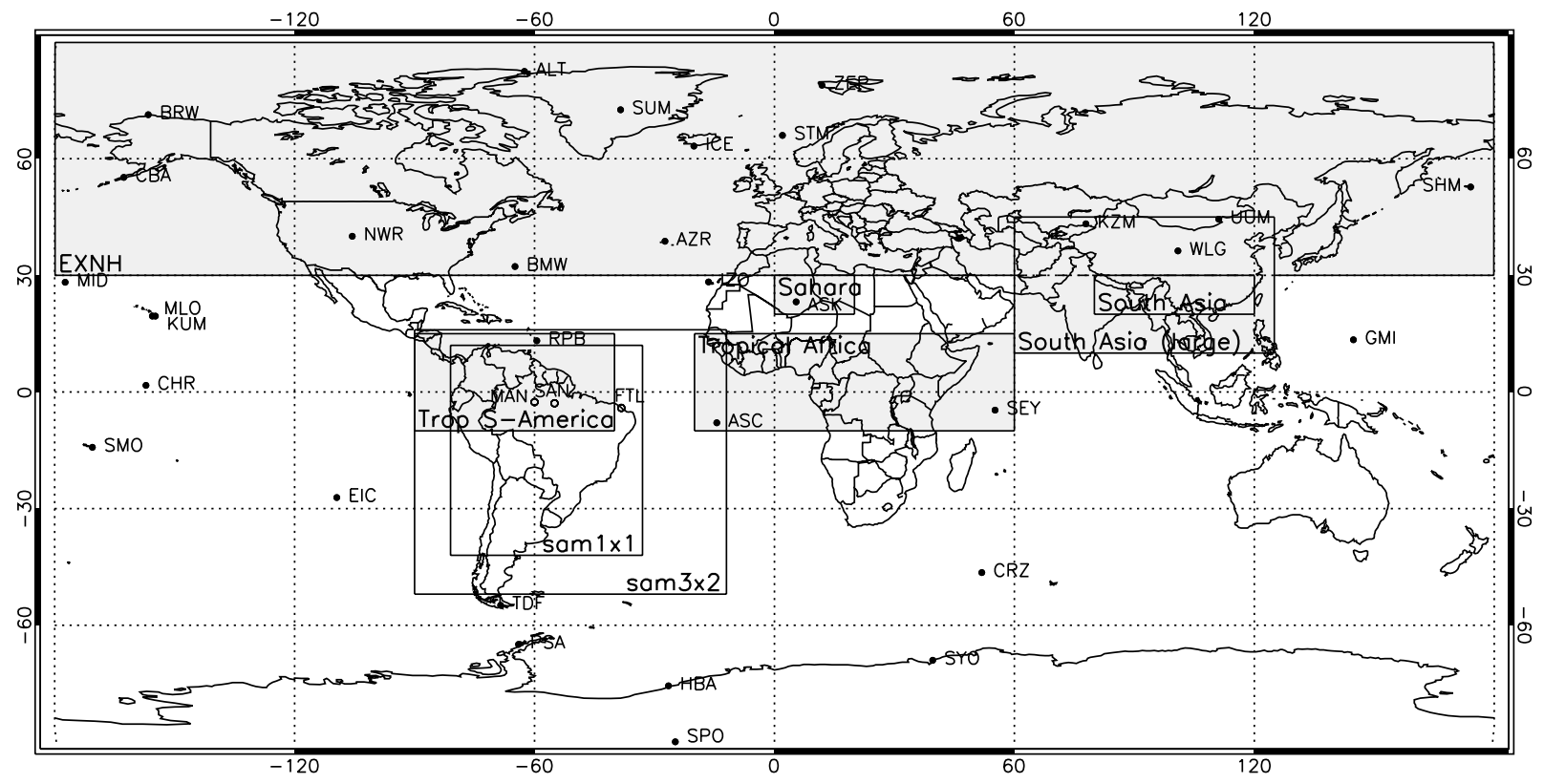

Figure 1. Locations of regions and sites used in this study. NOAA-ESRL measurement sites are indicated by solid dots. South American airborne measurement sites (SAN, MAN, FTL) are represented by open dots. Regions which are analyzed in detail in this study (EXNH (extratropical NH), Tropical South America, Tropical Africa, Sahara, and South Asia) are indicated by grey boxes. For South Asia a small region is used for analysis of SCIAMACHY observations, while a large region is used for analysis of emissions. Finally, the zoom regions of the TM5 model $(\operatorname{sam} 3 \times 2$ and sam $1 \times 1)$ are shown.

error covariance matrix. From this, the uncertainty reduction of the control vector achieved by assimilating observations can be calculated, defined here as $1-\sigma^{a} / \sigma^{b}$, where $\sigma^{b}$ and $\sigma^{a}$ denote prior and posterior errors, respectively. It turns out that a reduction in the norm of the cost function gradient by about ten orders of magnitude is needed to reach reasonable convergence of posterior error estimates. Therefore we iterate our inversions to this point, even if much less iterations would suffice to obtain stable estimates of posterior emissions.

\subsection{Observations}

[12] We use satellite observations of $\mathrm{CH}_{4}$ from the SCIAMACHY instrument. The observations have been obtained with retrieval version V1.1, as described in Frankenberg et al. [2006] and Bergamaschi et al. [2007]. In short, $\mathrm{CH}_{4}$ and $\mathrm{CO}_{2}$ column abundances are retrieved from SCIAMACHY radiance measurements in neighboring spectral regions in the near-infrared (fitting windows are 1631-1670 nm for $\mathrm{CH}_{4}$ and 1563-1585 nm for $\mathrm{CO}_{2}$ ). Column-averaged methane mixing ratio observations are obtained by taking the ratio of retrieved $\mathrm{CH}_{4}$ and $\mathrm{CO}_{2}$ columns, multiplied by column-averaged $\mathrm{CO}_{2}$ mixing ratios simulated by the TM3-MPI 3.8 model [Heimann and Körner, 2003]. We apply the same selection criteria for valid observations as in Frankenberg et al. [2006] including upper limits to the RMS residuals of the $\mathrm{CH}_{4}$ and $\mathrm{CO}_{2}$ retrievals and to the effective cloud-top height derived from the $\mathrm{CO}_{2}$ column observation.

[13] The individual SCIAMACHY pixels are $30 \mathrm{~km} \times$ $60 \mathrm{~km}$. In this study, the original observations are averaged on a regular $1^{\circ} \times 1^{\circ}$ longitude-latitude grid. The observa- tions are further averaged over 3-hourly assimilation time windows. Since consecutive SCIAMACHY orbits do not overlap for sub-polar latitudes (full global coverage is reached in six days), this basically means that no temporal averaging is performed. This is different from Bergamaschi et al. [2007], who used monthly averages. To produce observation equivalents, modeled $\mathrm{CH}_{4}$ fields are interpolated from the model resolution to a $1^{\circ} \times 1^{\circ}$ grid, and vertically integrated using the averaging kernels shown in Frankenberg et al. [2006].

[14] Methane surface observations from the NOAA ESRL global cooperative air sampling network [Dlugokencky et al., 1994, 2003] are also assimilated in 3-hourly assimilation windows. These observations are on the NOAA2004 methane dry-air mole fraction scale [Dlugokencky et al., 2005]. Since the global model domain has a relatively coarse resolution of $6^{\circ} \times 4^{\circ}$, it is difficult to simulate measurements in the vicinity of emission regions. Therefore only flask measurements from 32 marine and continental background sites, as listed in Table 1 of Bergamaschi et al. [2007], are used. The selected sites are also indicated in Figure 1.

[15] The uncertainty of the SCIAMACHY observations is fixed at $1.5 \%$ as in Bergamaschi et al. [2007]. This value accounts for unknown regional systematic errors rather than the random error which would be generally smaller [Bergamaschi et al., 2007; Frankenberg et al., 2006] (see also section 3.3). The measurement error for surface observations is assumed to be $3 \mathrm{ppb}$, in addition to which an estimate of the representativeness error is included, based on the $3 \mathrm{D}$ model gradient from the prior simulation 
[Bergamaschi et al., 2005]. All observation errors are assumed to be uncorrelated, i.e., $\mathbf{R}$ is diagonal.

\subsection{Inversion Set-Up}

[16] In this paper we investigate a three-month period (September-November 2003), in which SCIAMACHY observed high methane concentrations over large parts of the tropics and in particular over South America [Frankenberg et al., 2005, 2006]. 4D-Var is a particularly attractive tool for assimilating a large number of observations in combination with a large control vector, as is the case here. Furthermore, the zoom option of TM5 is useful here to analyze the South American continent in detail.

[17] The TM5 model is run at a global resolution of $6^{\circ} \times 4^{\circ}$ with zooming via $3^{\circ} \times 2^{\circ}$ to $1^{\circ} \times 1^{\circ}$ nested grids over South America as depicted in Figure 1. The inversions start at 1 September 2003 and continue until 10 December 2003. The beginning of December is included because the SCIAMACHY observations in this period contain information on emissions for November. Emissions for December are optimized but not reported in this paper.

[18] The prior emissions in this study are identical to the prior emissions used in the ' $\mathrm{JK}$ ' scenario of Bergamaschi et al. [2007]. We refer to Tables 2 and 3 of that paper for a description of the applied bottom-up inventories and resulting yearly total emissions for the 11 source categories distinguished. For most categories the a priori uncertainty of monthly grid-scale emissions is assumed to be $50 \%$. For enteric fermentation a lower uncertainty of 30\% is applied, while for wetlands and biomass burning a higher uncertainty of $80 \%$ is used. Information on spatial correlations of emission errors is generally lacking. Therefore we specify spatial error correlations simply by Gaussian functions of distance. The correlation lengths $L_{\mathbf{s}_{i}}$ are set to $500 \mathrm{~km}$ for all categories. This length scale can be interpreted as the effective spatial scale at which emissions are optimized. Emission errors are assumed to be strongly correlated in time, since most bottom-up inventories are in fact yearly data sets. Therefore temporal error correlations are specified by exponential functions with correlation lengths $\tau_{\mathbf{s}}$ of 9.5 months, corresponding to a rather high month-to-month correlation of 0.9. Exceptions are the source categories wetlands, rice cultivation and biomass burning, for which temporal error correlations are set to zero, because emissions (and thus presumably errors in emissions) from these categories vary strongly in time. Errors in emissions from different categories are assumed to be uncorrelated. The prior initial concentration field comes from an inversion using only surface observations over 2003. Prior errors in the initial concentration field vary with altitude but are typically $10 \mathrm{ppb}$ in the troposphere. The horizontal spatial error correlation length $L_{\mathbf{c}}$ is assumed to be $500 \mathrm{~km}$.

[19] The control vector $\mathbf{x}$ consists of emissions for 11 source categories and 4 months and the initial concentration distribution. Furthermore, a parameter vector $\mathbf{p}$ is included, which contains 3 coefficients per month describing an assumed bias in the SCIAMACHY observations as a second-order polynomial in latitude. The coefficients have no a priori constraints. This large-scale bias correction was introduced by Bergamaschi et al. [2007] in order to reconcile the SCIAMACHY observations with model simulations that were consistent with the NOAA-ESRL surface measurements. The motivation for assuming a month- and latitude-dependent bias is that a number of potential causes of systematic errors, e.g., errors in $\mathrm{CH}_{4}$ spectroscopy, lead to a bias in the observations that is proportional to the air-mass factor, which is in turn a function of the solar zenith angle and thus of latitude and month. Many other potential sources of systematic errors exist (for example aerosols; see also Bergamaschi et al. for a detailed discussion), which cannot be described as a function of latitude. Moreover, there may also be systematic errors in the model. However, since the origin of biases in the SCIAMACHY observations is unclear at the moment, we have chosen to stick to the present rather simple bias model. It should be realized that unresolved biases in the observations directly lead to biases in derived emission estimates.

[20] Observations and their errors are as described in section 2.2 . In total, $\approx 10^{5}$ satellite observations and $\approx 400$ surface observations are assimilated, compared to a control vector dimension of $\approx 4 \times 10^{4}$. The inversions are carried out in two cycles. In the second cycle only those observations are assimilated that differ by less than three times the observation error from the posterior model simulation of the first cycle.

[21] Apart from the inversion scenario as described above (termed I1), a number of sensitivity inversions (I2 to I11) have been performed. These are described in Table 1.

\section{Results From the Reference Inversion 3.1. Convergence}

[22] In Meirink et al. [2008] the convergence of the 4DVar system is discussed in detail. However, this is for a case in which only a small number of surface observations were assimilated. The addition of SCIAMACHY data gives many more constraints to the inversion. Thus it is expected that more iterations in the minimization procedure are needed before convergence is reached. Convergence in the reference scenario I1 is reached in 48 iterations, indeed more than the 32 iterations needed for an analogous inversion with only surface observations (scenario I2), but not much more.

[23] Figure 2 shows the convergence characteristics for inversion scenario I1, which is typical for a case with satellite data. The largest eigenvalue (which is the condition number of the Hessian matrix) is $10^{8}, 4$ orders of magnitude larger than in scenario I2, reflecting the much larger number of assimilated observations. At 12 iterations, there is a sudden downward jump of the eigenvalues. This number corresponds exactly to the number of bias parameters ( 3 polynomial coefficients for 4 months) in the control vector. These parameters can be considered as large-scale patterns, which are very well constrained by the combined use of satellite and surface observations. They are associated with large eigenvalues, and are determined in the first 12 iterations. In subsequent iterations, the emissions are optimized, as is clearly visible in Figure 2c, showing the convergence of the uncertainty reduction of emissions aggregated over the globe, all months, and all categories. Indeed, this uncertainty reduction is zero in the first 12 iterations, and converges in subsequent iterations toward a value of 0.66 .

\subsection{Emissions}

[24] The optimized emissions resulting from the inversion are plotted in Figure 3. The most notable features are a 
Table 1. Description of Sensitivity Inversions

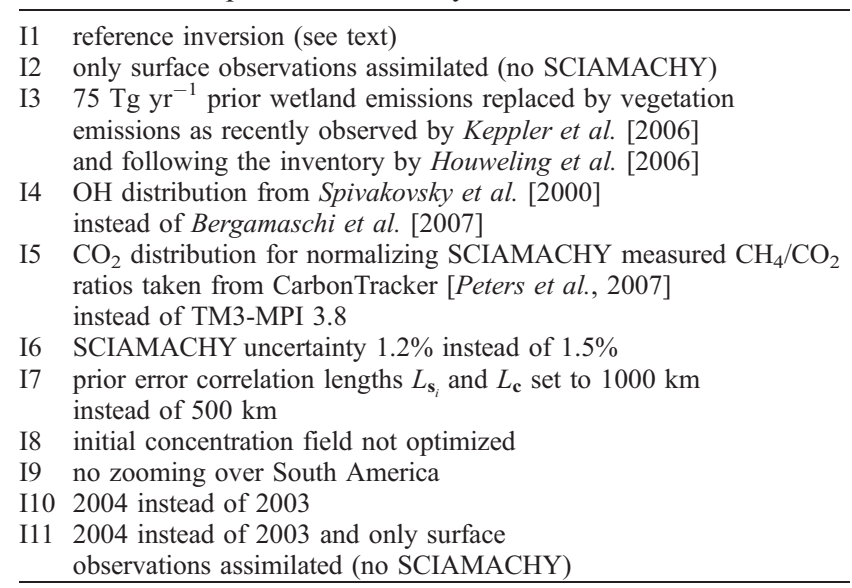

decrease in emissions from South Asia, an increase in emissions from the tropics, and a decrease in emissions from northern hemispheric $(\mathrm{NH})$ high latitudes. In Figure 4 the emission increments are shown for 3 out of the 11 source categories distinguished. Wetlands constitute globally the largest (and most uncertain) methane source. Therefore the bulk of the emission increments are attributed to this source. Both the enhancements in the tropics and the decreases at high $\mathrm{NH}$ latitudes are mainly related to wetland emissions. In South Asia, rice cultivation is the most important methane source in this part of the year. The strong decrease in emissions from rice cultivation resulting from the inversion is related to the specific time period chosen in our inversion. In a 1-year inversion, the total rice emissions are not much reduced but rather the timing is changed, such that emissions peak earlier in the year [see Bergamaschi et al., 2007]. In South America, biomass burning is, after wetlands, the most important source in the months September through November. Biomass burning emissions are strongly enhanced in the inversion. Apart from the three categories shown in Figure 4 other categories contribute regionally to the emission increments. For example, the decreases in the Middle East are related to oil and gas production, the decreases in East China are attributed to waste handling, and the 1-grid-cell increase near Novosibirsk (Siberia) is related to coal mining. It should be noted that the observations cannot distinguish between methane emitted by the various source categories. Thus attribution to different source categories relies on the assumed prior spatio-temporal emission error distributions.

[25] The satellite observations have a modest effect on the estimated global total emissions (Table 2). However, on regional/continental scales they induce large increments. For example, the total emissions from tropical South America increase from $10.0 \mathrm{Tg} \mathrm{CH}_{4}$ a priori to $21.1 \mathrm{Tg} \mathrm{CH}_{4}$ a posteriori. Other regions, e.g., South Asia, show reductions in emissions of similar magnitude. In our inversions, the surface fluxes are not forced to remain positive. Indeed, negative (significantly lower than zero) posterior emissions are derived for some grid boxes (Figure 3), which may either point to regional systematic errors in the satellite observations or to model biases, e.g., in transport or in the prior emission distributions.

\subsection{Comparison With SCIAMACHY Observations}

\subsubsection{Spatial Distribution}

[26] The global distribution of the number of assimilated SCIAMACHY observations is far from homogeneous (Figure 5). The largest amounts of valid observations are located over regions with a high surface albedo and few clouds, particularly deserts. At high latitudes the large solar zenith angle hampers retrieval, over dark surfaces (such as forests) the signal-to-noise ratio is often too low, and over the ocean a useful retrieval can only be performed if the ground scene is covered with low clouds which have a high albedo.

[27] As mentioned before, the SCIAMACHY observations are corrected for a latitude-dependent bias, which is estimated in the inversion procedure. The resulting bias estimates are shown in Figure 6. These bias functions are mainly determined by the regions with a high density of observations, notably the deserts. Our approach to estimate
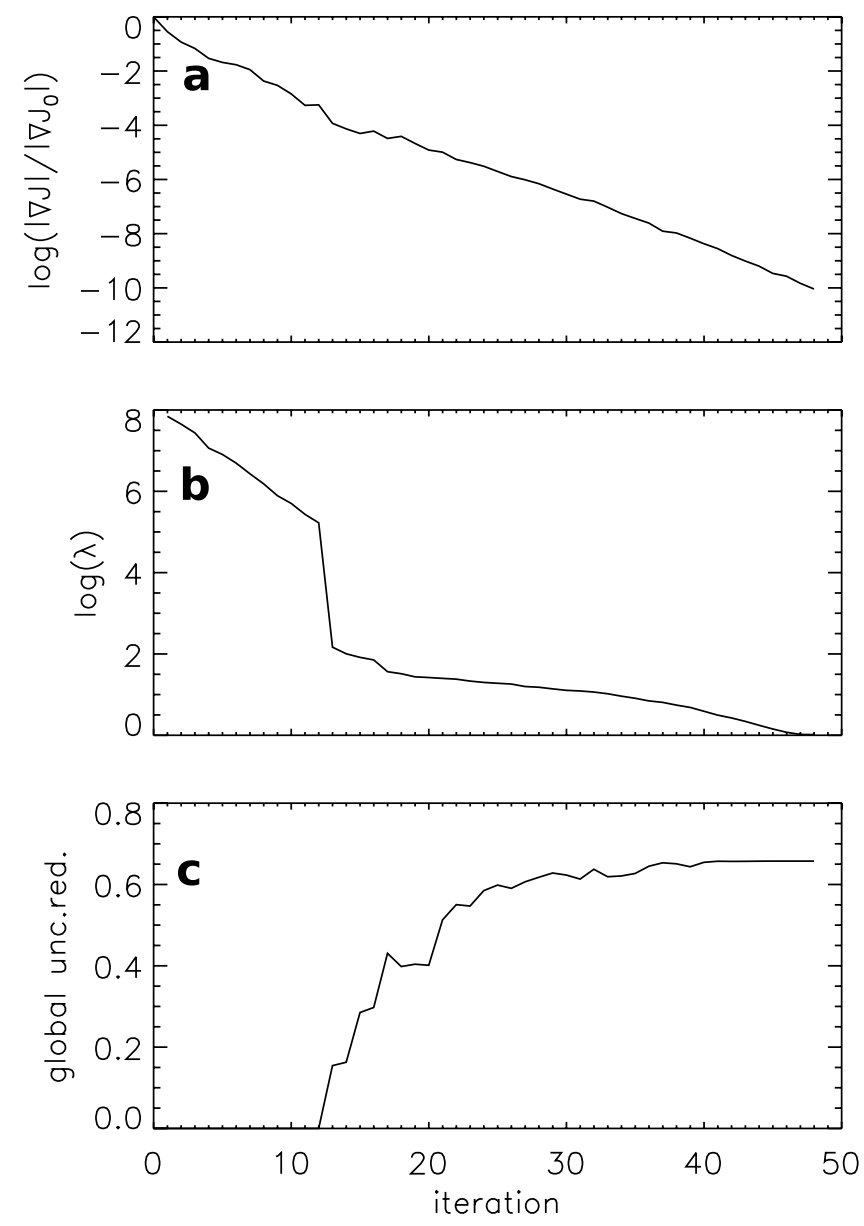

Figure 2. Convergence of the 4D-Var minimization for inversion scenario I1. As a function of iteration the following are shown: (a) the $\log$ of the norm of the cost function gradient relative to the prior simulation, (b) the $\log$ of the eigenvalue of the Hessian, and (c) the uncertainty reduction of emissions aggregated over the globe, all months, and all categories. 

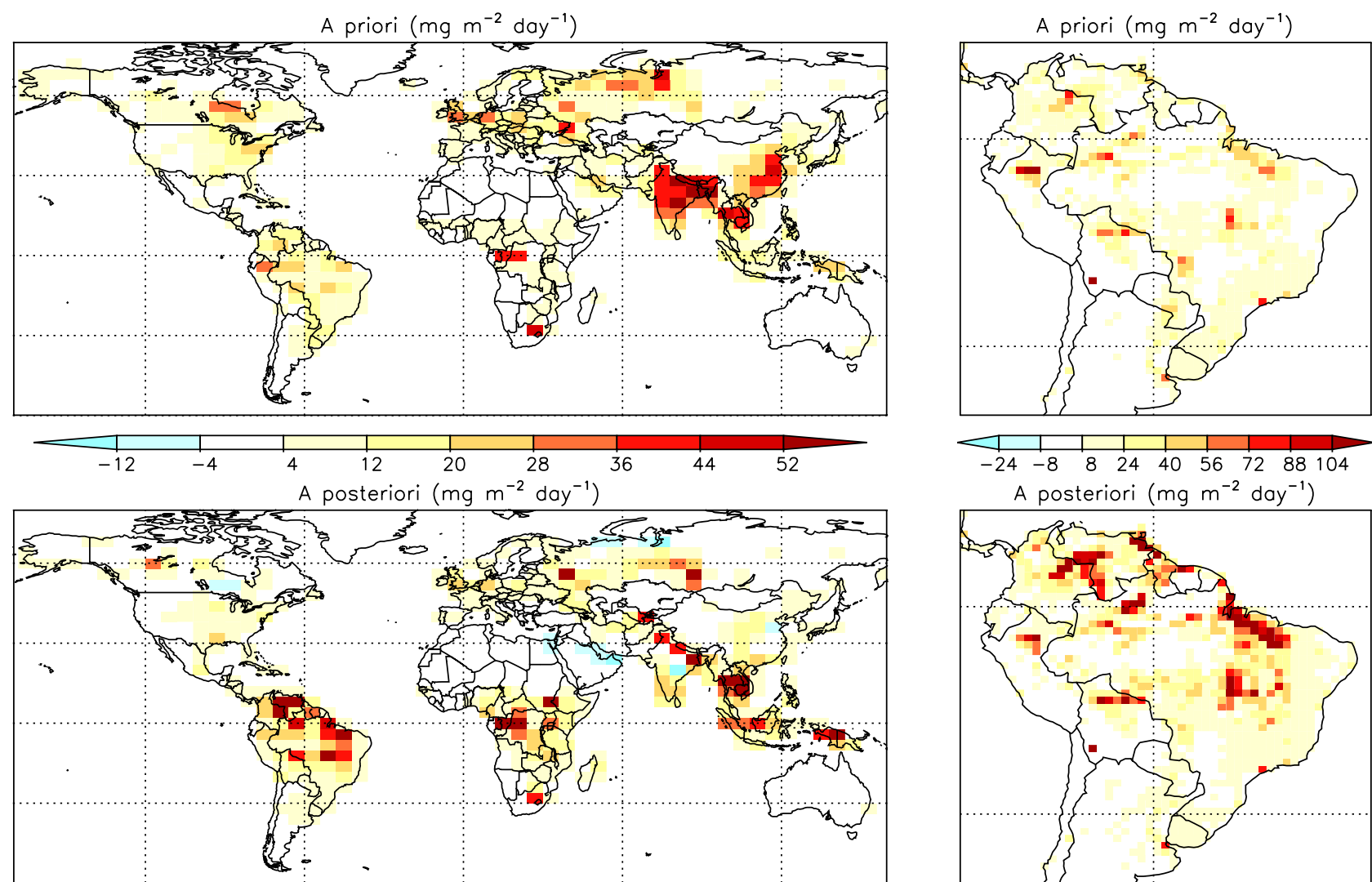

-84
A posteriori ( $\left(\mathrm{mg} \mathrm{m} \mathrm{m}^{-2} \mathrm{day}^{-1}\right)$
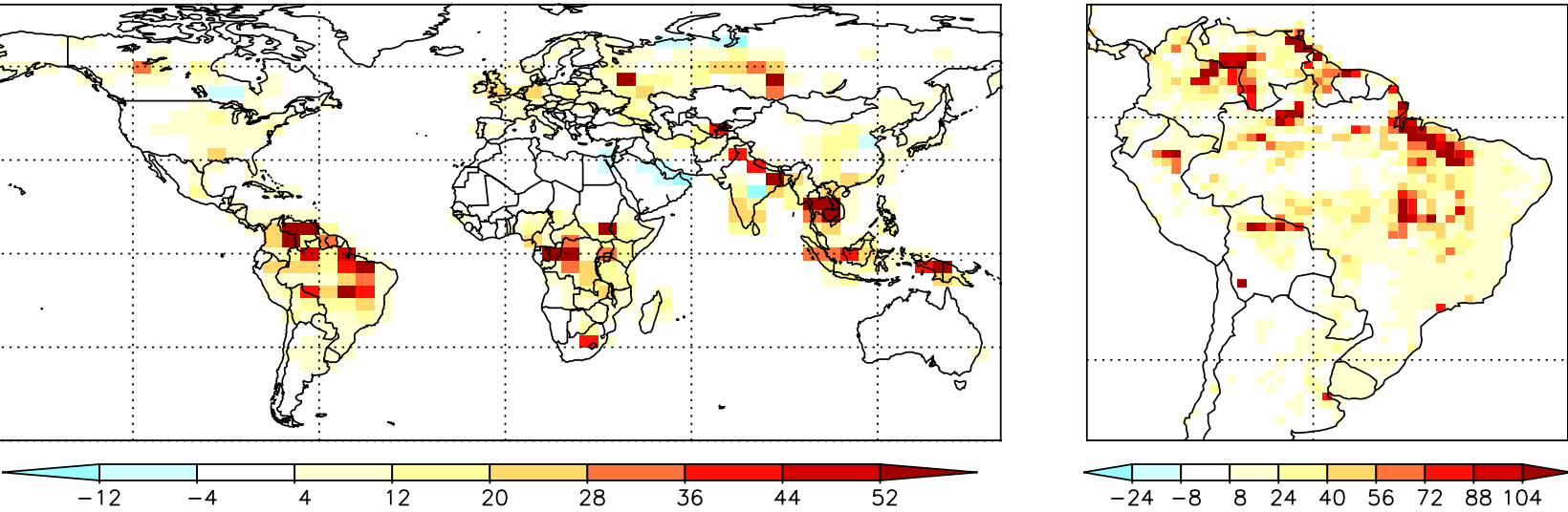

posteriori - priori $\left(\mathrm{mg} \mathrm{m}^{-2} \mathrm{day}^{-1}\right)$
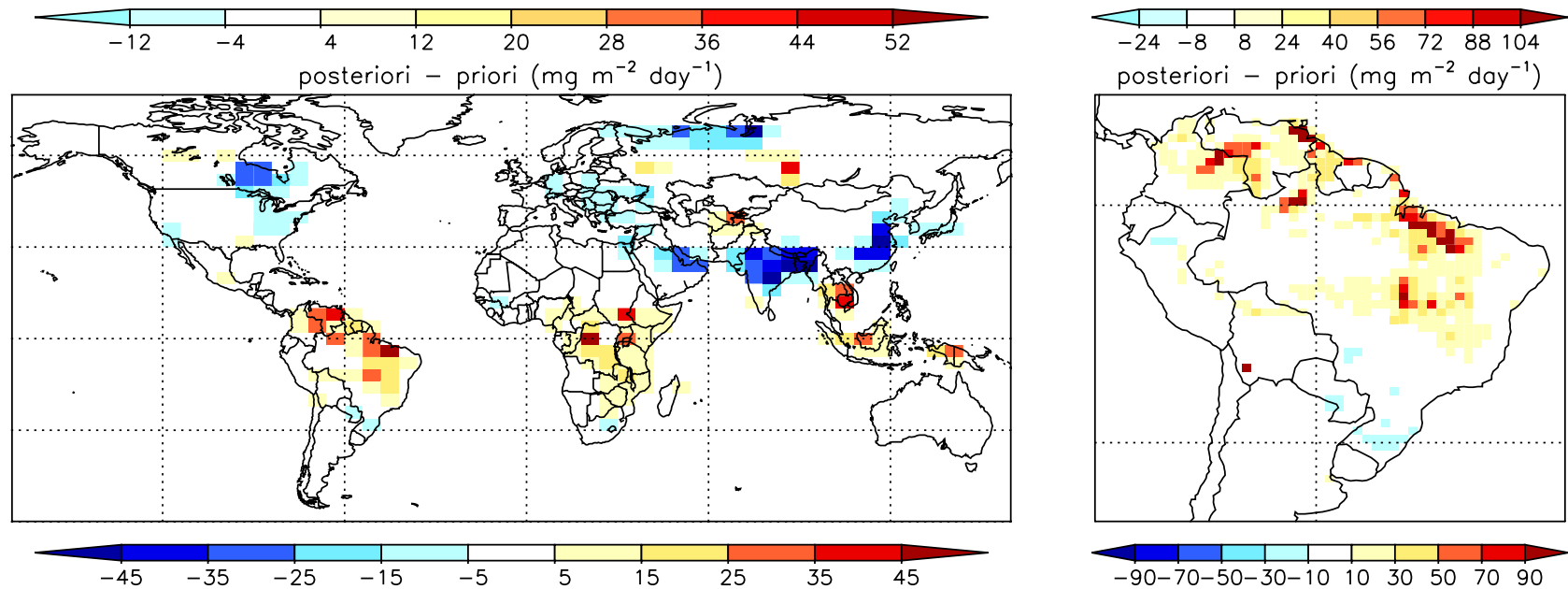

$-90-70-50-30-101030507090$

Figure 3. Emissions from September to November 2003 for reference inversion (scenario I1): (top) a priori, (middle) a posteriori, and (bottom) a posteriori - a priori increment. The (left) global maps are on $6^{\circ} \times 4^{\circ}$ resolution; the (right) maps of South America are on $1^{\circ} \times 1^{\circ}$ resolution. Units are $\mathrm{mg} \mathrm{m}^{-2} \mathrm{day}^{-1}$.

only three polynomial coefficients per month, in combination with the wealth of satellite data and an accurate reference provided by the surface observations, leads to a very well constrained bias correction with posterior uncertainties of only a few ppb. The bias corrections are very similar to those obtained in Bergamaschi et al. [2007] (see their Figure 6 where prior to the inversion the SCIAMACHY observations had been scaled by a factor 0.98 , which explains the different offset). The corrections are substantial, and the difference between the estimates for November and September/October is quite large. This might indicate that the time resolution of the applied bias correction is not high enough. Given the rather ad-hoc and empirical character of the bias model, some interference of the bias correction with the estimated emissions is to be expected. However, since the exact underlying physical processes have not yet been unambiguously identified, we stick to the present relatively simple approach.

[28] Figure 7 shows a comparison of SCIAMACHY observations with prior and posterior model simulations. The bias-corrected observations and prior model simulation are similar to the plots presented in Frankenberg et al. 

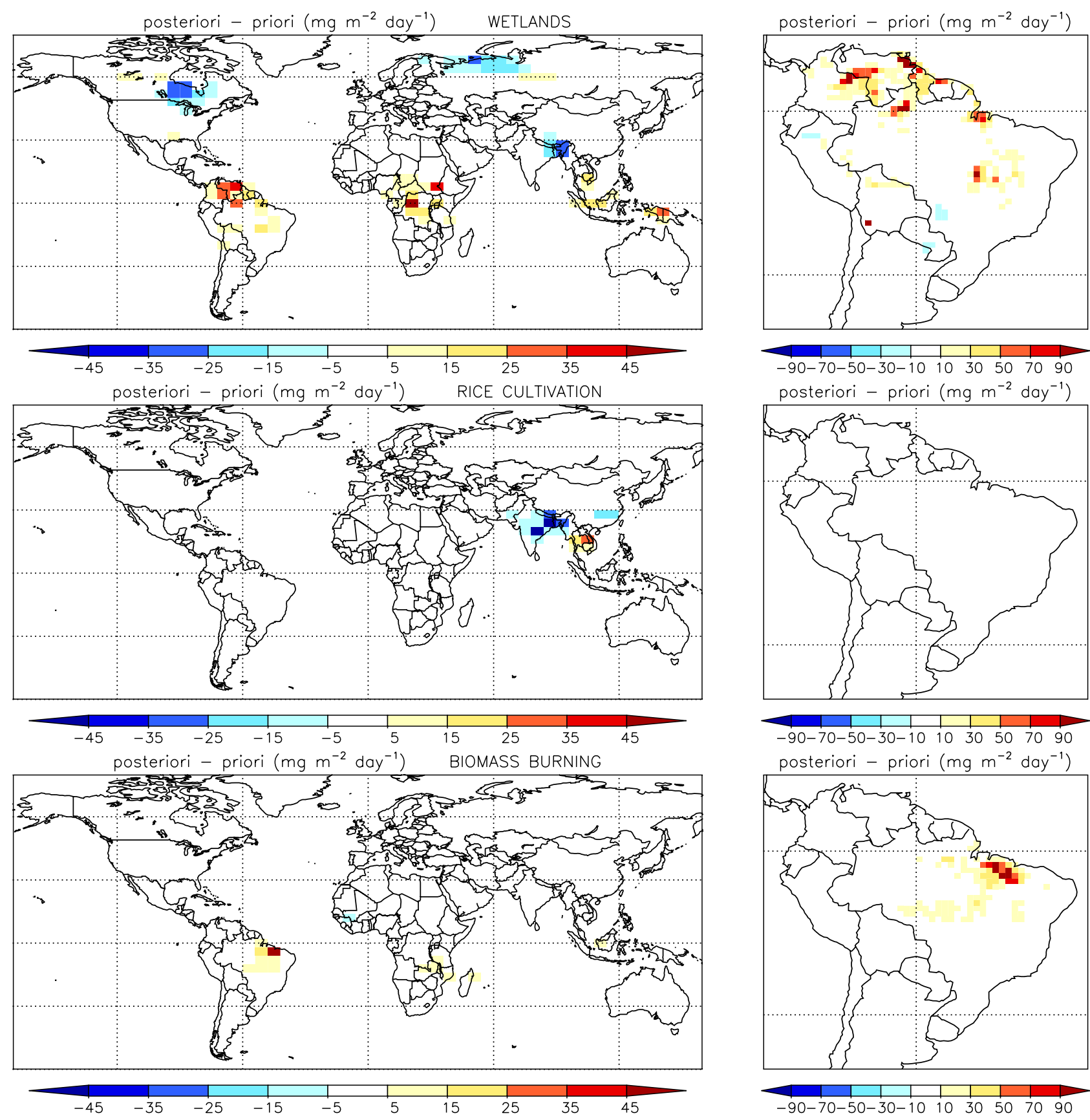
posteriori - priori ( $\mathrm{mg} \mathrm{m} \mathrm{m}^{-2} \mathrm{day}^{-1}$ )
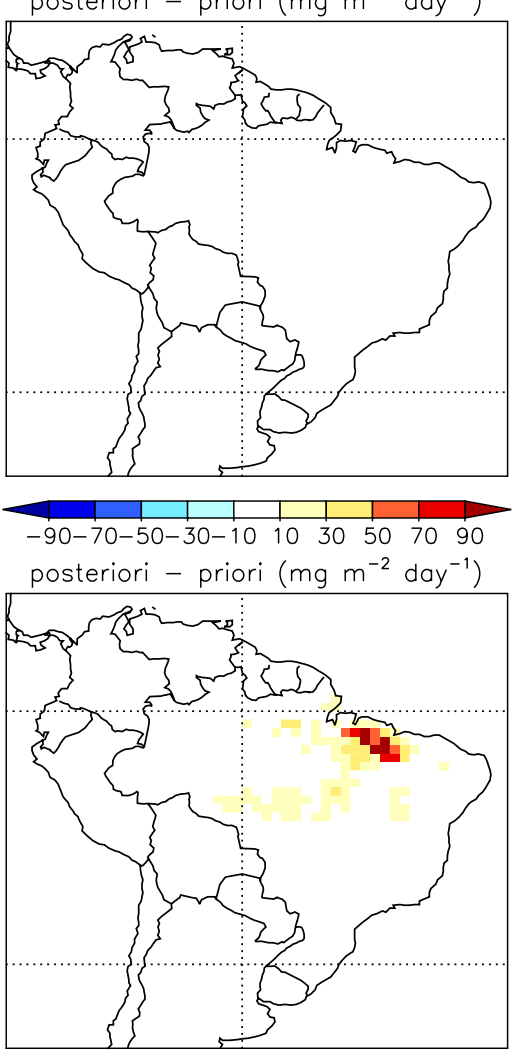

$-90-70-50-30-101030507090$

Figure 4. Emission increments for three source categories: (top) wetlands, (middle) rice cultivation, and (bottom) biomass burning. The (left) global maps are on $6^{\circ} \times 4^{\circ}$ resolution; the (right) maps of South America are on $1^{\circ} \times 1^{\circ}$ resolution.

[2005], although in that study different retrieval and model versions were used, and the bias correction consisted of a single global scaling factor applied to the SCIAMACHY observations. The largest differences are present in the tropics, where the model underestimates the observed concentrations, and in South Asia, where the model overestimates the observations. The assimilation corrects most of these differences, resulting in a generally very good agreement between the observations and the posterior simulation. Concentration differences between posterior and prior model simulations range from $-50 \mathrm{ppb}$ in South Asia to $+50 \mathrm{ppb}$ in South America.
[29] The synthesis inversion of Bergamaschi et al. [2007] could not effectively match the small-scale patterns in the SCIAMACHY observations in South America in the second half of the year (see their Figure 10). The overall good fit of the SCIAMACHY data obtained in the present inversion can be attributed to the grid-based inversion approach, which clearly illustrates the power of 4D-Var.

[30] There are two types of locations where the posterior simulation still differs substantially from the observations. First, over large mountains such as the Himalayas and the Andes, the modeled concentrations remain much lower than observed. This is likely due to systematic errors in the 
Table 2. Prior and Posterior Emissions From September to November $\left(\mathrm{Tg} \mathrm{CH}_{4}\right)$ and Uncertainty Reduction for Selected Regions (see Figure 1) and for Inversion Scenarios I1 to I11 as Described in Table 1

\begin{tabular}{|c|c|c|c|c|c|c|c|c|c|c|c|c|}
\hline & & $\mathrm{I} 1$ & $\mathrm{I} 2$ & $\mathrm{I} 3$ & $\mathrm{I} 4$ & $\mathrm{I} 5$ & I6 & $\mathrm{I} 7$ & I8 & I9 & $\mathrm{I} 10$ & $\mathrm{I} 11$ \\
\hline \multirow[t]{3}{*}{ Globe } & prior & 127.9 & 127.9 & 129.3 & 127.9 & 127.9 & 127.9 & 127.9 & 127.9 & 127.9 & 127.9 & 127.9 \\
\hline & posterior & 128.4 & 127.6 & 130.4 & 136.2 & 127.9 & 129.8 & 132.8 & 128.0 & 130.4 & 128.1 & 119.0 \\
\hline & uncertainty reduction & 0.66 & 0.51 & 0.60 & 0.64 & 0.61 & 0.66 & 0.80 & 0.66 & 0.67 & 0.70 & 0.53 \\
\hline \multirow{3}{*}{ EXNH } & prior & 47.9 & 47.9 & 45.2 & 47.9 & 47.9 & 47.9 & 47.9 & 47.9 & 47.9 & 47.9 & 47.9 \\
\hline & posterior & 33.8 & 38.9 & 34.3 & 33.7 & 34.8 & 32.7 & 32.0 & 33.7 & 33.7 & 28.8 & 34.0 \\
\hline & uncertainty reduction & 0.84 & 0.73 & 0.61 & 0.85 & 0.85 & 0.92 & 0.83 & 0.84 & 0.80 & 0.74 & 0.68 \\
\hline \multirow{3}{*}{ Tropical South America } & prior & 10.0 & 10.0 & 10.7 & 10.0 & 10.0 & 10.0 & 10.0 & 10.0 & 10.0 & 10.0 & 10.0 \\
\hline & posterior & 21.1 & 13.2 & 20.9 & 23.5 & 19.9 & 21.5 & 21.7 & 21.2 & 21.6 & 21.5 & 12.5 \\
\hline & uncertainty reduction & 0.67 & 0.19 & 0.46 & 0.58 & 0.65 & 0.65 & 0.75 & 0.65 & 0.60 & 0.66 & 0.13 \\
\hline \multirow[t]{3}{*}{ Tropical Africa } & prior & 8.8 & 8.8 & 9.8 & 8.8 & 8.8 & 8.8 & 8.8 & 8.8 & 8.8 & 8.8 & 8.8 \\
\hline & posterior & 19.1 & 14.1 & 19.8 & 21.2 & 18.6 & 20.0 & 21.0 & 19.2 & 19.3 & 21.3 & 13.7 \\
\hline & uncertainty reduction & 0.61 & 0.20 & 0.65 & 0.60 & 0.61 & 0.63 & 0.70 & 0.61 & 0.62 & 0.66 & 0.15 \\
\hline \multirow[t]{3}{*}{ South Asia } & prior & 40.8 & 40.8 & 42.0 & 40.8 & 40.8 & 40.8 & 40.8 & 40.8 & 40.8 & 40.8 & 40.8 \\
\hline & posterior & 24.4 & 37.5 & 24.8 & 24.0 & 25.6 & 24.6 & 24.4 & 24.2 & 24.7 & 25.7 & 34.8 \\
\hline & uncertainty reduction & 0.81 & 0.31 & 0.83 & 0.82 & 0.77 & 0.78 & 0.83 & 0.81 & 0.80 & 0.83 & 0.32 \\
\hline
\end{tabular}

retrievals for large surface elevations, since elevation information was not included in the prior [see also Bergamaschi et al., 2007]. Second, over the oceans the model generally shows higher concentrations than observed. This might point to a land-ocean bias related to the fact that retrievals over the ocean are solely possible in the presence of (low) clouds or sun glint. However, it should be noted that the derived bias correction is dominated by the land retrievals. Hence any systematic error over land (e.g., due to aerosols) would also lead to a systematic land-ocean difference.

\subsubsection{Regional Statistics and Time Series}

[31] In Figure 8 observations and model simulations are compared in terms of histograms for specific regions defined in Figure 1 (the regions are the same as analyzed by Frankenberg et al. [2006]). In general it should be noted that the histograms are approximated well by Gaussian distributions. This gives confidence in the Gaussian treatment of observation errors in the assimilation system, although the requirement of unbiased observation errors is clearly not met.
[32] The Sahara is a region where high-precision observations can be obtained because of cloud-free conditions and a high surface albedo. The occurrence of dense dust aerosol loadings in the atmosphere could deteriorate the precision of the observations, although Frankenberg et al. [2006] showed that the ratio of retrieved $\mathrm{CH}_{4}$ and $\mathrm{CO}_{2}$ columns, which we use as observations, is relatively weakly affected by the presence of aerosols. As can be seen in Figure 8, the standard deviation between model (both prior and posterior) and observations is about $11.5 \mathrm{ppb}(\approx 0.7 \%)$. Assuming that model (including emission) errors and representativity errors play a minor role here, this number can be interpreted as the precision (random error) of 3-hourlyand $1^{\circ} \times 1^{\circ}$-averaged SCIAMACHY observations under near-optimal conditions. Since the gridded SCIAMACHY observations correspond on average to about 2 individual observations, this would translate to a precision of approximately $\sqrt{2} \times 0.7 \%=1 \%$ for the latter, consistent with the estimate of Frankenberg et al. [2006]. The SCIAMACHY bias at this latitude is estimated to be $42.5 \mathrm{ppb}$, i.e., almost

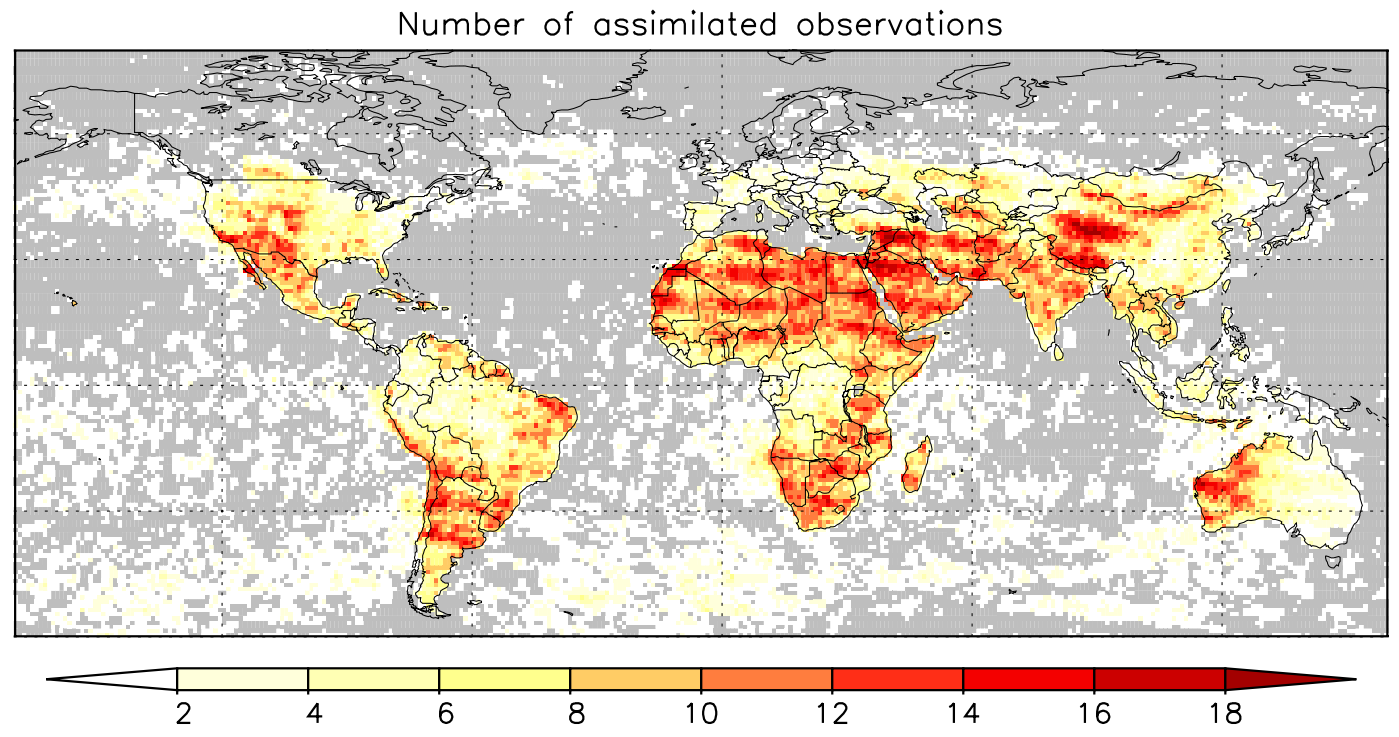

Figure 5. Number of assimilated SCIAMACHY observations per $1^{\circ} \times 1^{\circ}$ grid box from 1 September until 1 December 2003. 


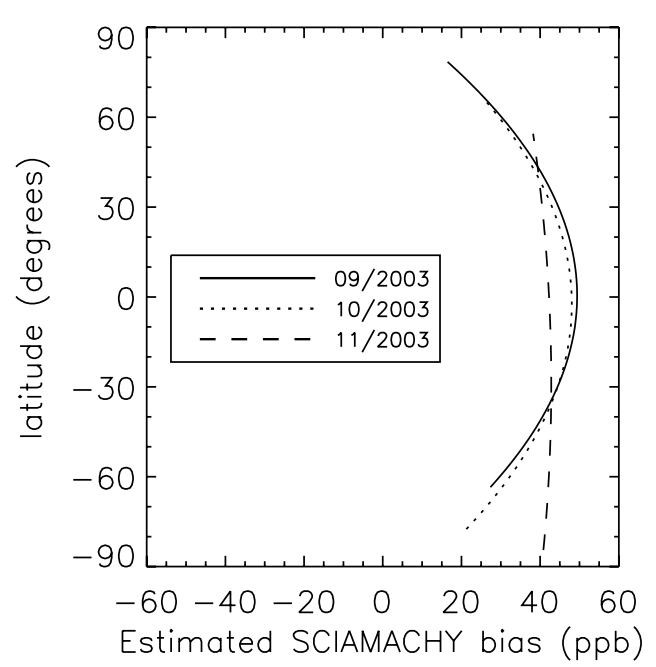

Figure 6. Estimate of monthly bias in SCIAMACHY observations. The bias is modeled as a second-order polynomial function in latitude.

$2.5 \%$. Note again that this bias correction largely replaces the global scaling factors applied in Frankenberg et al. [2005] and Frankenberg et al. [2006] Since the Sahara is relatively far away from emission regions, the histograms of bias-corrected observations minus prior and posterior model simulations are almost identical.

[33] Tropical South America is characterized by standard deviations of 22-24 ppb, twice as large as over the Sahara, pointing to an observation precision better than $1.3 \%$ (translating to $\approx 1.8 \%$ for individual observations). This is still lower than our prior observation error estimate of $1.5 \%$, but that estimate was meant to partly reflect regional systematic errors as well. The a priori difference between observations and model over South America is very large (77 ppb). The inversion attributes this partly ( $45 \mathrm{ppb})$ to a bias in the SCIAMACHY observations and partly (26 ppb) to an underestimate of emissions in the model. As a result, a posterior mismatch of only $5 \mathrm{ppb}$ remains. The changes in emissions also lead to a small (2 ppb) reduction of the standard deviation.

[34] For South Asia, the situation is different. After bias correction, the model strongly overestimates the observations, which is corrected by lowering the emissions, leading to a $23 \mathrm{ppb}$ decrease in modeled concentrations and a virtually vanishing posterior bias. The improvement in terms of standard deviation is about $4 \mathrm{ppb}$, thus better than for tropical South America.

[35] Finally, for tropical Africa the observation-model difference largely vanishes after the bias correction. The emission increments do not have a large impact on the mean concentration over the region. This seems at odds with the strong enhancements seen in Figure 7, but can be explained by the fact that most observations are located in the north and east of the region, where concentration increments are small. Related to the heterogeneity of the region is the relatively large $(6 \mathrm{ppb})$ reduction in the observation-model standard deviation due to optimized emissions.

[36] In Figure 9, the measured and modeled concentrations are averaged over the same large regions and plotted as a time series. For the Sahara, the model and observations are on average in good agreement, but the observations show variations of about $20 \mathrm{ppb}$, which are much weaker in the model simulations. We verified that these variations in the observations are not related to the specific part of the region covered by observations on a certain day. At this point it is unclear whether the variations are real or an observational artifact, e.g., related to aerosols.

[37] For tropical South America, the estimated increase in emissions leads to an increase in modeled concentrations of about 25-30 ppb during most of the assimilation period, except for the beginning of September, when the prior model simulation is already in reasonable agreement with the observations. The considerable day-to-day variability in the observations $(10-20 \mathrm{ppb})$ is fairly well reproduced by the inversion.

[38] In South Asia both the SCIAMACHY observations and the model show a decrease in $\mathrm{CH}_{4}$ concentrations during the assimilation period. This decrease corresponds to a return to 'background' conditions after a large $\mathrm{CH}_{4}$ emission pulse from rice cultivation. However, our prior estimate still has considerable rice emissions in September and October [see also Frankenberg et al., 2006; Bergamaschi et al., 2007], which are strongly reduced in the inversion to reproduce the satellite observations.

[39] Finally, for tropical Africa observed concentrations are higher than the prior model simulation in the first two months, which is corrected by enhanced posterior emissions. The inversion seems to underestimate the satellite observations severely in the beginning of September, but there are only few observations in this period, which hardly constitute a constraint in the inversion.

\section{Sensitivity Experiments}

[40] In this section, sensitivity experiments are presented in which potentially important assumptions and settings in the inversion set-up are modified. This gives an indication of the robustness of the results. An overview of the sensitivity inversions is given in Table 1. Emissions and chi-squared statistics resulting from the sensitivity experiments are presented in Tables 2 and 3, respectively.

\subsection{Emissions}

[41] The largest modification to the reference scenario I1 is made in scenario I2, in which the SCIAMACHY observations are withdrawn from the inversion. From these experiments a consistent picture of the impact of SCIAMACHY observations emerges. On the (sub-)continental scale, the emission increments in inversions I1 and I2 have the same sign (increased emissions in the tropics; decreased emissions at $\mathrm{NH}$ high latitudes and in the rice areas in South Asia), but the increments are greatly magnified when SCIAMACHY observations are included. For 2004 (scenarios I10 and I11) qualitatively very similar emission increments are obtained, suggesting that interannual variability of the main regional features is relatively small. The surface observations suggest considerably lower global total emissions in 2004 than in 2003 (emission increments are -0.3 and $-8.9 \mathrm{Tg} \mathrm{CH}_{4}$ in scenarios I2 and I11, respectively). In contrast, the inversions with SCIAMACHY observations yield negligible global emission increments for both 2003 and $2004(0.5$ and $0.2 \mathrm{Tg}$ 

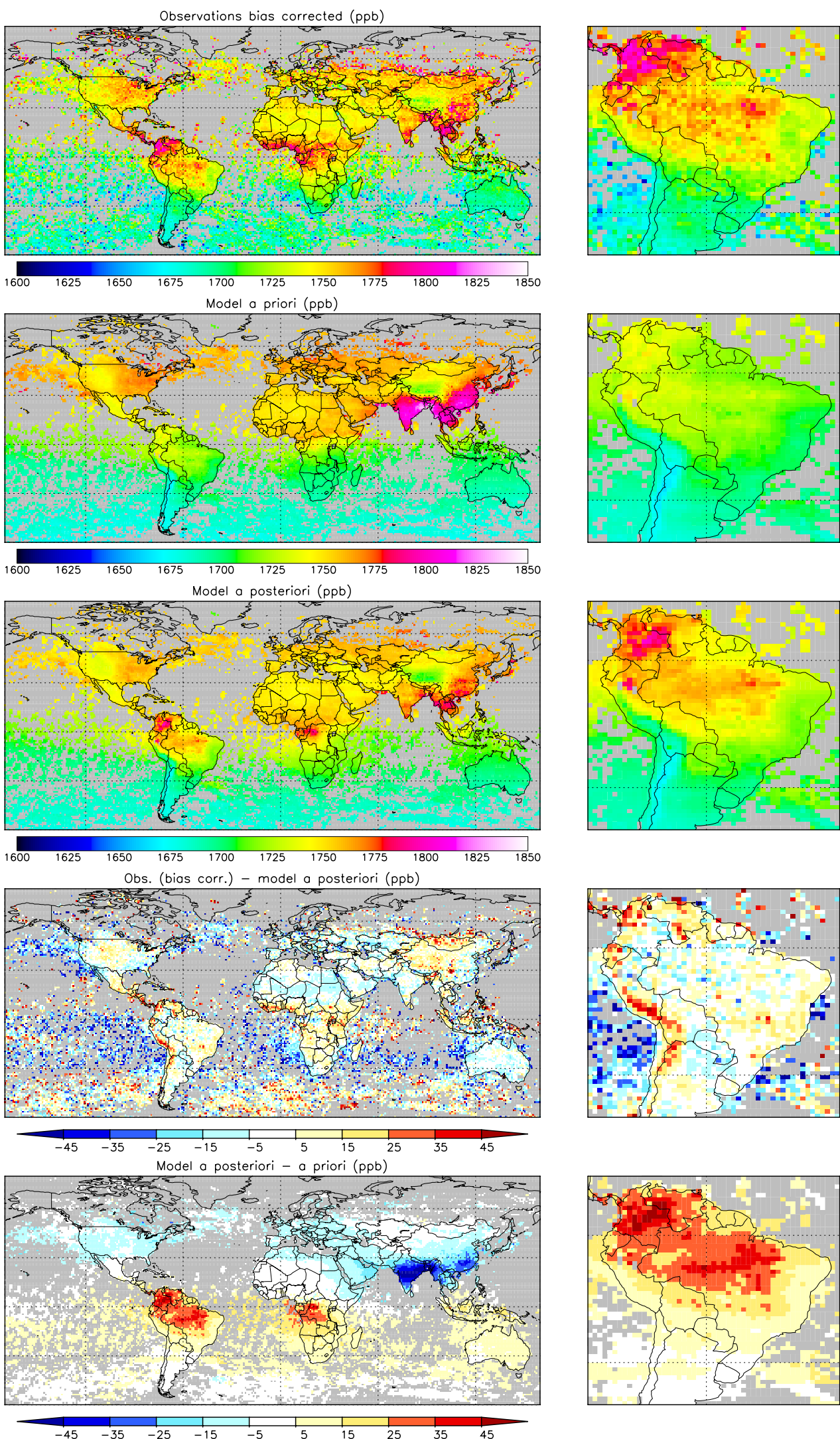

Figure 7. Column-averaged $\mathrm{CH}_{4}$ mixing ratios from (top) SCIAMACHY observations, (second row) model a priori, (third row) a posteriori, (fourth row) observations minus a posteriori, and (bottom) a posteriori minus a priori. Observations are corrected for a bias as shown in Figure 6. Observations and model output are averaged over the months September through November 2003 and binned on a $1^{\circ} \times 1^{\circ}$ grid. Units are ppb. 

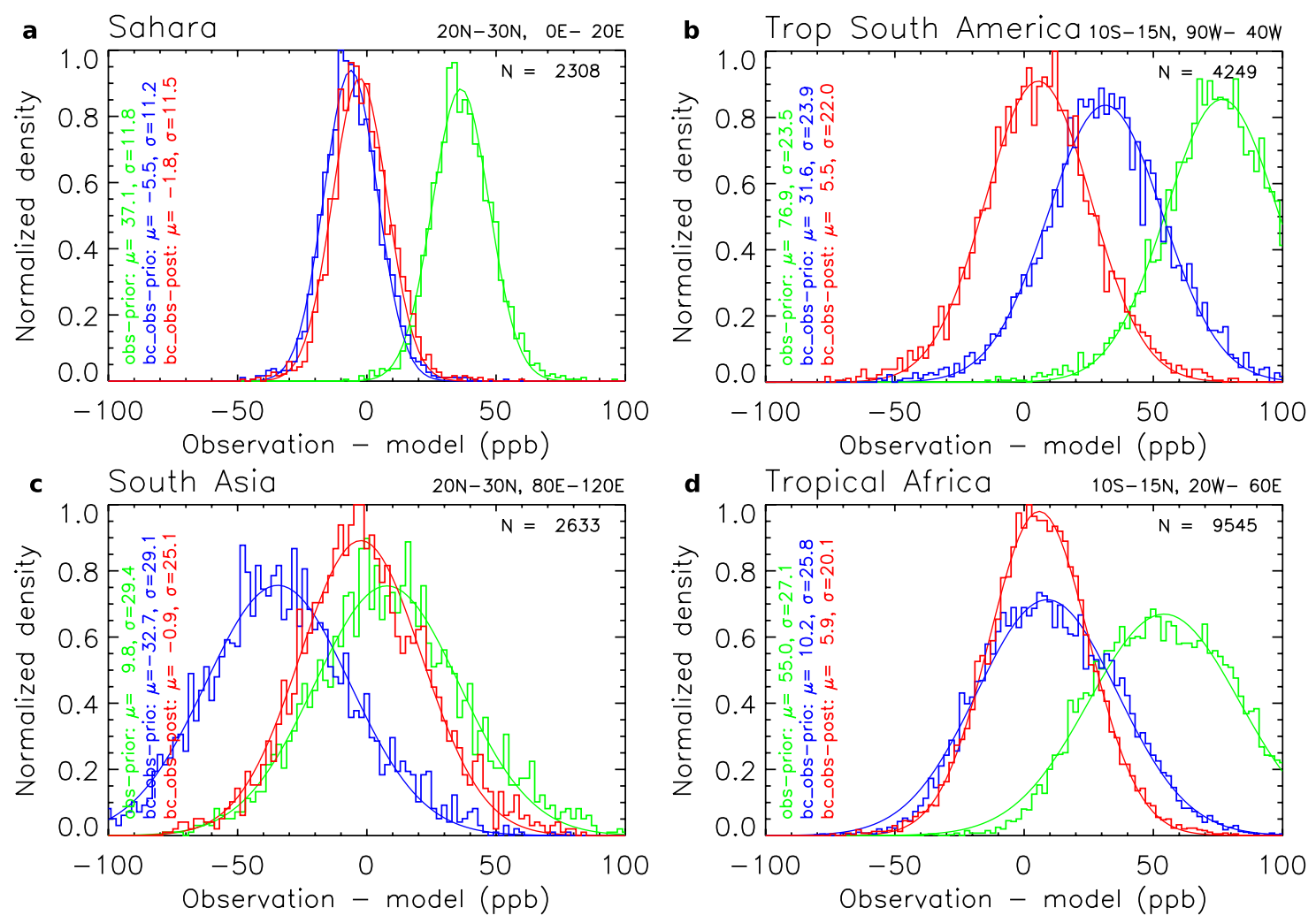

Figure 8. Histograms of SCIAMACHY-minus-model differences over (a) the Sahara, (b) tropical South America, (c) South Asia, and (d) tropical Africa. Green lines show uncorrected SCIAMACHY observations minus a priori model simulation, blue lines show bias-corrected observations minus a priori model simulation, and red lines show bias-corrected observations minus a posteriori model simulation. The histograms have been normalized relative to the concentration bin with the largest number of observations. Gaussian fits to the histograms are represented by solid lines. For each region, the total number of assimilated observations and the observation-minus-model bias and standard deviation are indicated in the plots.

$\mathrm{CH}_{4}$ in scenarios I1 and $\mathrm{I10}$, respectively). This result is hard to interpret since the global increment is the net aggregation of considerable regional increases and decreases, and the bias correction to the satellite data could also play a role in the exact outcome.

[42] Scenarios I3 to I9 were designed to check the impact of a broad range of assumptions and settings in the reference inversion I1. It is reassuring that on the (sub-)continental scale the emission increments obtained from all perturbed inversions are much closer to scenario I1 than to I2, demonstrating that the impact of SCIAMACHY observations as described above is not just an artifact related to one of the assumptions tested here. Analyzing the emission increments in more detail, we can certainly find some differences. For example, scenario I4, in which an alternative OH distribution from Spivakovsky et al. [2000] is applied, yields significantly larger global total emissions, resulting mainly from larger tropical emissions. This result is readily explained by the fact that the Spivakovsky et al. $\mathrm{OH}$ field has much higher concentrations over the tropical continents than our reference $\mathrm{OH}$ field. A second example is the larger emission increments estimated in experiment I7. The larger error correlation lengths applied in this experiment lead to both stronger reductions in the $\mathrm{NH}$ high latitudes and stronger enhancements in the tropics, espe- cially in Africa. The likely explanation is that, since the same grid-scale prior uncertainties have been used, aggregated prior uncertainties are larger in I7 than in I1, thus allowing larger emission increments.

[43] Figure 10 shows the spatial distribution of emissions increments for three sensitivity inversions. They should be compared to the reference inversion I1 (Figure 3c). First of all, leaving out the SCIAMACHY observations (scenario I2) strongly influences emissions in the tropics and South Asia. Emissions at higher $\mathrm{NH}$ latitudes are much less affected. Indeed, at high latitudes the surface fluxes are relatively more constrained by the surface observations (see below). The second plot shows an inversion with emissions from vegetation (scenario I3), as recently discovered by Keppler et al. [2006] but later questioned by Dueck et al. [2007]. The vegetation emissions are modeled as in Houweling et al. [2006], proportional to leaf area index and monthlymean $\mathrm{NO}_{2}$ photolysis rates, and replace part of the a priori wetland emissions. Scenario I3 yields generally somewhat smaller increments than the reference inversion. This is because the total prior emissions in I 3 are higher in the tropics and lower at $\mathrm{NH}$ high latitudes. Therefore smaller adjustments are needed to match the satellite observations. Also, the distribution of vegetation emissions is more spatially homogeneous compared to wetlands, thus yielding 

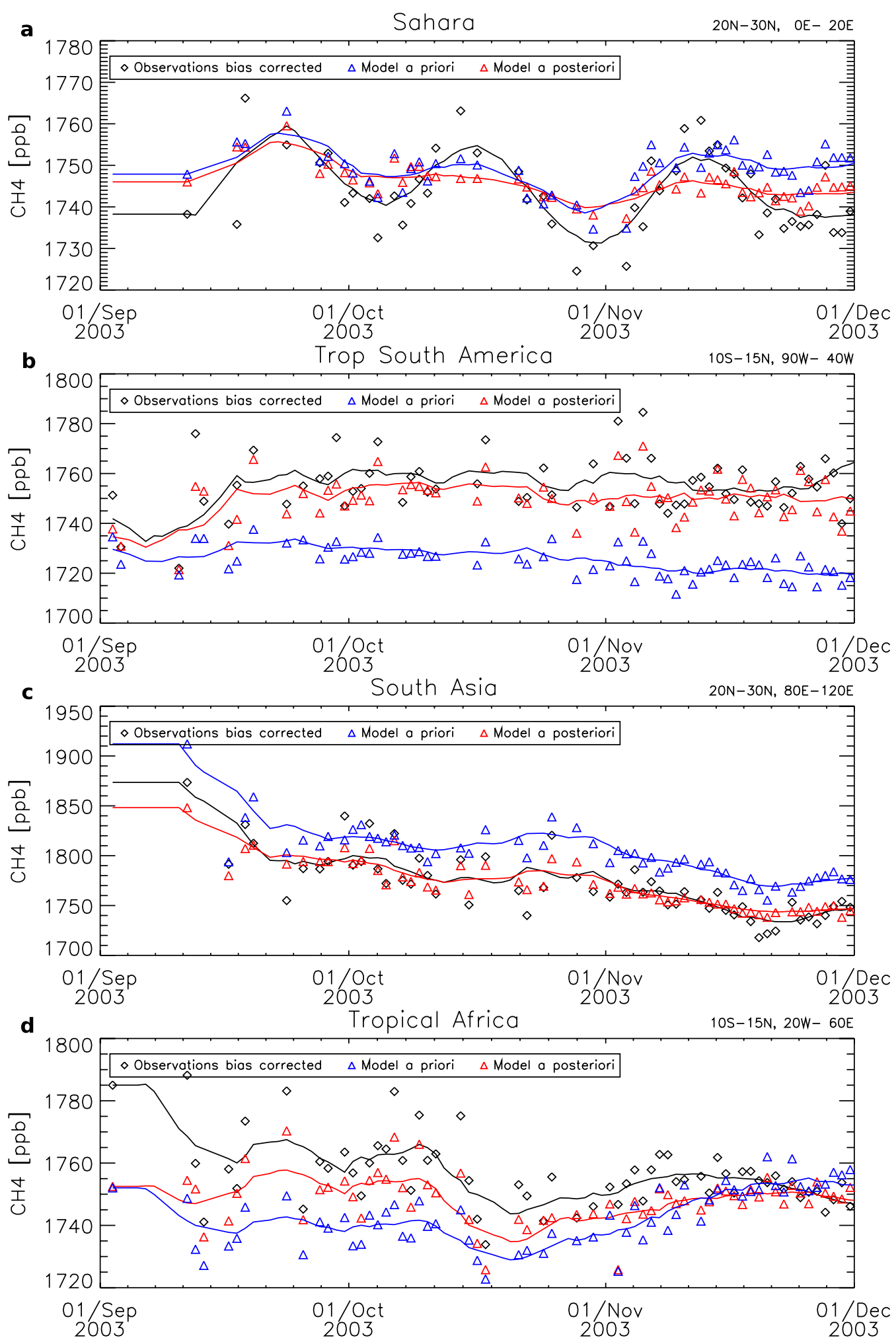

Figure 9. Time series of (black) SCIAMACHY bias-corrected observations, (blue) prior model simulation and (red) posterior model simulation, averaged over (a) the Sahara, (b) tropical South America, (c) South Asia, and (d) tropical Africa. The symbols show daily means. The solid lines, representing 10-day running averages, have been added as a guide to the eye. 
Table 3. $\chi^{2} / n$ Statistics with Respect to Surface and SCIAMACHY Observations for Selected Regions (Figure 1) and for Inversion Scenarios I1 to I11 Described in Table $1^{\text {a }}$

\begin{tabular}{|c|c|c|c|c|c|c|c|c|c|c|c|c|}
\hline & & I1 & $\mathrm{I} 2$ & $\mathrm{I} 3$ & I4 & I5 & I6 & $\mathrm{I} 7$ & I8 & I9 & $\mathrm{I} 10$ & $\mathrm{I} 11$ \\
\hline \multirow[t]{5}{*}{ Surface Globe } & $n 1$ & 400 & 400 & 400 & 400 & 400 & 400 & 400 & 400 & 400 & 385 & 385 \\
\hline & prior 1 & 7.54 & 7.54 & 5.12 & 9.29 & 7.54 & 7.54 & 7.54 & 7.54 & 6.97 & 9.59 & 9.59 \\
\hline & post. 1 & 1.99 & 1.82 & 2.21 & 1.95 & 1.91 & 2.16 & 2.05 & 2.09 & 1.76 & 1.60 & 1.17 \\
\hline & $n_{\text {out }} 1$ & 19 & 10 & 21 & 17 & 15 & 21 & 18 & 23 & 13 & 12 & 7 \\
\hline & post. 2 & 1.17 & 1.20 & 1.28 & 1.19 & 1.17 & 1.24 & 1.18 & 1.16 & 1.18 & 1.17 & 0.96 \\
\hline \multirow[t]{5}{*}{ SCIA Globe } & $n 1$ & 98190 & & 98190 & 98190 & 98190 & 98186 & 98190 & 98190 & 98190 & 130719 & \\
\hline & prior 1 & 0.96 & & 0.95 & 1.05 & 0.90 & 1.52 & 0.97 & 0.97 & 0.97 & 0.99 & \\
\hline & post. 1 & 0.63 & & 0.63 & 0.63 & 0.62 & 0.97 & 0.62 & 0.64 & 0.62 & 0.62 & \\
\hline & $n_{\text {out }} 1$ & 237 & & 230 & 237 & 226 & 866 & 227 & 238 & 226 & 322 & \\
\hline & post. 2 & 0.60 & & 0.60 & 0.60 & 0.60 & 0.86 & 0.59 & 0.61 & 0.59 & 0.59 & \\
\hline \multirow{5}{*}{ SCIA Sahara } & $n 1$ & 2308 & & 2308 & 2308 & 2308 & 2308 & 2308 & 2308 & 2308 & 3448 & \\
\hline & prior 1 & 0.22 & & 0.22 & 0.20 & 0.21 & 0.33 & 0.20 & 0.22 & 0.21 & 0.17 & \\
\hline & post. 1 & 0.19 & & 0.19 & 0.19 & 0.19 & 0.29 & 0.19 & 0.19 & 0.19 & 0.15 & \\
\hline & $n_{\text {out }} 1$ & 0 & & 0 & 0 & 0 & 0 & 0 & 0 & 0 & 1 & \\
\hline & post. 2 & 0.19 & & 0.19 & 0.19 & 0.19 & 0.29 & 0.19 & 0.19 & 0.19 & 0.14 & \\
\hline \multirow[t]{5}{*}{ SCIA Tropical South America } & $n 1$ & 4256 & & 4256 & 4256 & 4256 & 4256 & 4256 & 4256 & 4256 & 6611 & \\
\hline & prior 1 & 2.13 & & 2.02 & 2.89 & 1.84 & 3.44 & 2.23 & 2.15 & 2.25 & 1.94 & \\
\hline & post. 1 & 0.72 & & 0.71 & 0.74 & 0.71 & 1.08 & 0.71 & 0.72 & 0.70 & 0.75 & \\
\hline & $n_{\text {out }} 1$ & 7 & & 4 & 8 & 7 & 38 & 7 & 7 & 5 & 16 & \\
\hline & post. 2 & 0.70 & & 0.69 & 0.71 & 0.69 & 0.98 & 0.68 & 0.70 & 0.68 & 0.68 & \\
\hline \multirow[t]{5}{*}{ SCIA tropical Africa } & n 1 & 9557 & & 9557 & 9557 & 9557 & 9557 & 9557 & 9557 & 9557 & 12106 & \\
\hline & prior 1 & 1.06 & & 1.03 & 1.23 & 0.96 & 1.68 & 1.09 & 1.06 & 1.09 & 1.21 & \\
\hline & post. 1 & 0.61 & & 0.60 & 0.62 & 0.59 & 0.91 & 0.57 & 0.62 & 0.62 & 0.64 & \\
\hline & $n_{\text {out }} 1$ & 11 & & 11 & 11 & 10 & 47 & 10 & 11 & 11 & 17 & \\
\hline & post. 2 & 0.60 & & 0.58 & 0.60 & 0.58 & 0.85 & 0.56 & 0.60 & 0.60 & 0.62 & \\
\hline \multirow[t]{5}{*}{ SCIA South Asia } & $n 1$ & 2647 & & 2647 & 2647 & 2647 & 2647 & 2647 & 2647 & 2647 & 2820 & \\
\hline & prior 1 & 2.68 & & 2.76 & 2.60 & 2.57 & 4.14 & 2.59 & 2.68 & 2.65 & 2.77 & \\
\hline & post. 1 & 0.89 & & 0.89 & 0.89 & 0.90 & 1.37 & 0.91 & 0.89 & 0.89 & 0.95 & \\
\hline & $n_{\text {out }} 1$ & 9 & & 9 & 10 & 10 & 50 & 9 & 9 & 9 & 24 & \\
\hline & post. 2 & 0.85 & & 0.85 & 0.85 & 0.85 & 1.17 & 0.86 & 0.85 & 0.85 & 0.86 & \\
\hline
\end{tabular}

a“" $n 1$ " and " $n_{\text {out }} 1$ " are the number of assimilated observations and the number of posterior outlier observations (posterior model simulation and observation differ more than three times the observation error) in the first inversion cycle, respectively. "prior 1" and "post. 1" are the a priori and a posteriori $\chi^{2} / n$ in the first inversion cycle, respectively. "post. 2" is the a posteriori $\chi^{2} / n$ in the second cycle. For the calculation of all $\chi^{2} / n$ with respect to SCIAMACHY, the bias-corrected observations are used.

more homogeneous emission increments. Finally, scenario I10 produces qualitatively the same picture as the reference inversion, but there are many differences in the details. For example, the positive flux increment near Novosibirsk is much weaker in the 2004 inversion and the enhancements in central Brazil are weaker and more spatially spread out. This suggests that there is indeed some interannual variability on regional scales, but the main global emission patterns as observed by SCIAMACHY and the surface network are similar in 2003 and 2004.

\subsection{Uncertainty Reduction}

[44] We now turn our attention to the posterior uncertainties estimated by the 4D-Var algorithm. Figure 11 shows that grid-scale uncertainty reductions in the reference inversion go up to around $50 \%$ for some grid boxes, and are highest in the tropics and South Asia. In South America six more or less separate regions with visible uncertainty reductions can be distinguished. Two of those regions (just north of Bolivia and near the north coast of Brazil) are related to biomass burning, the others to wetland emissions. These six regions are characterized by high prior emission rates, and consequently large prior uncertainties (cf. Figure 3 ). However, they are not (strictly) the regions where the largest emission increments occur. For example, large emission increments are present in North-East Venezuela, but their associated uncertainty reduction is small.
[45] When SCIAMACHY observations are withdrawn from the assimilation (scenario I2), the grid-scale uncertainty reduction in the tropics and South Asia is reduced to almost zero. At the NH high latitudes, surface observations give the main constraint, resulting in similar posterior error estimates with and without SCIAMACHY observations. The uncertainty reduction is at some locations (e.g., Alaska) even larger in scenario I2 than in I1. The probable explanation for this feature is that inversion I1 first optimizes the large-scale patterns in the satellite observations. Small-scale uncertainty reductions around some surface stations are not yet obtained within the number of iterations performed.

[46] Estimates of the uncertainty reductions aggregated over large regions converge much faster, and these estimates are reasonably robust after about 40 iterations Table 2 lists the uncertainty reductions over 5 different large regions for all sensitivity inversions. This again shows that the added value of SCIAMACHY is highest in the tropics (e.g., uncertainty reduction increases from 0.19 to 0.67 over tropical South America by adding SCIAMACHY observations), and is modest at higher latitudes (e.g., uncertainty reduction increases from 0.73 to 0.84 in "EXNH"), and on the global scale (increase from 0.51 to 0.66 ).

[47] The estimates of uncertainty reduction for scenarios I3 to I9 are generally similar to I1. There is one exception: experiment I7, which has larger a priori error correlation lengths, yields generally larger uncertainty reduction. There are two reasons for this. Most importantly, as noted in 

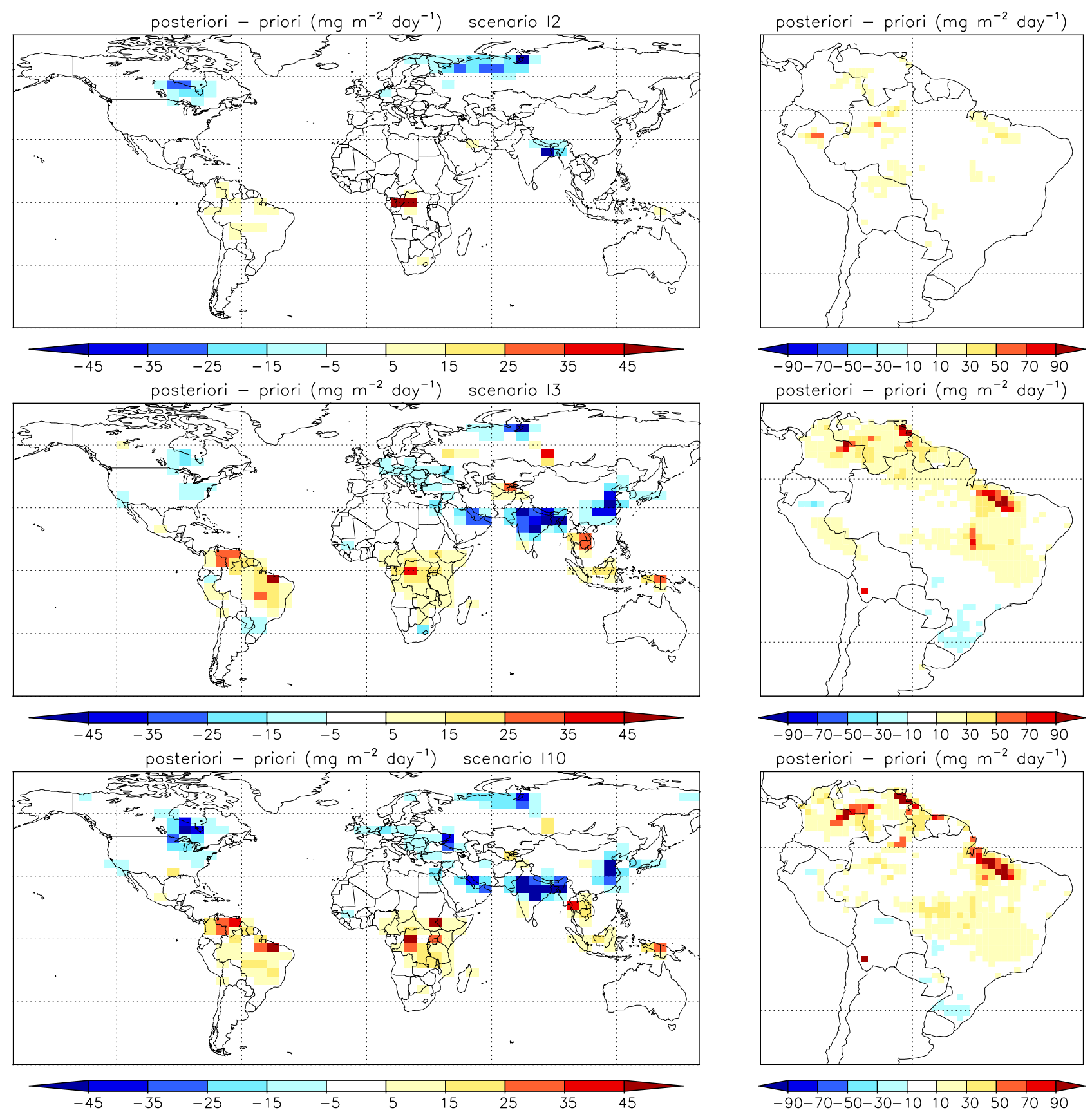

Figure 10. A posteriori - a priori emission increments for three sensitivity inversions: (top) I2 with only surface observations assimilated, (middle) I3 with part of wetland prior emissions replaced by vegetation emissions, and (bottom) I10 which covers the year 2004 instead of 2003. (left) The global maps are on $6^{\circ} \times 4^{\circ}$ resolution; (right) the maps of South America are on $1^{\circ} \times 1^{\circ}$ resolution.

section 4.1, the (aggregated) prior errors are larger in I7, thus leaving more room for error reduction. Secondly, the region of influence of the observations is larger in $\mathrm{I}$, so that they effectively constrain the emissions in more grid cells. Figure 11 shows that the global locations of uncertainty reduction are the same in inversions $\mathrm{I} 1$ and $\mathrm{I7}$, but in scenario I7 the values are larger and the patterns are more spatially extended. For example, in South America the six separate regions with significant uncertainty reduction in I1 merge to two or three larger regions in I7. A lesson to be learned from these sensitivity inversions is that calculated uncertainty reductions depend strongly on prior assumptions. This should be considered when conclusions are drawn with respect to the information on emission rates present in the observations.

\subsection{Fit to Observations}

[48] The fit to the observations is measured by the chisquared, defined here as:

$$
\chi^{2}=\sum_{i=1}^{n}\left(\frac{\left((\mathbf{H x})_{i}-\mathbf{y}_{i}\right)}{\sigma_{\mathbf{y}_{i}}}\right)^{2}
$$



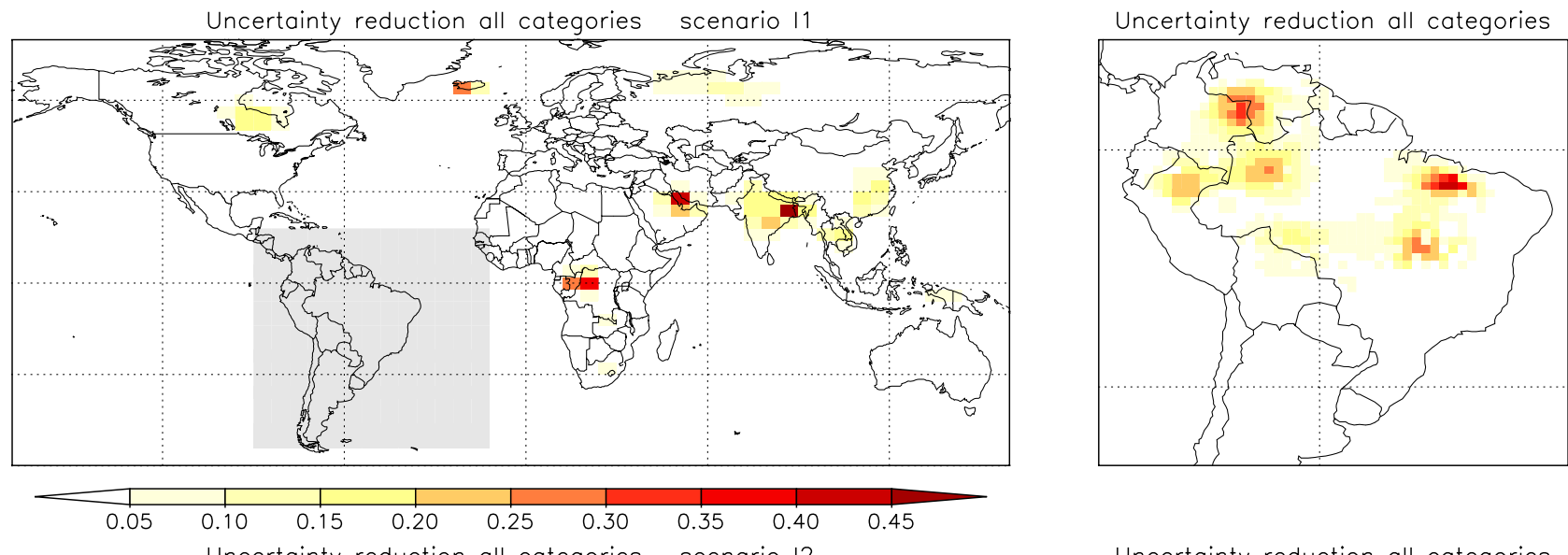

Uncertainty reduction all categories scenario 12
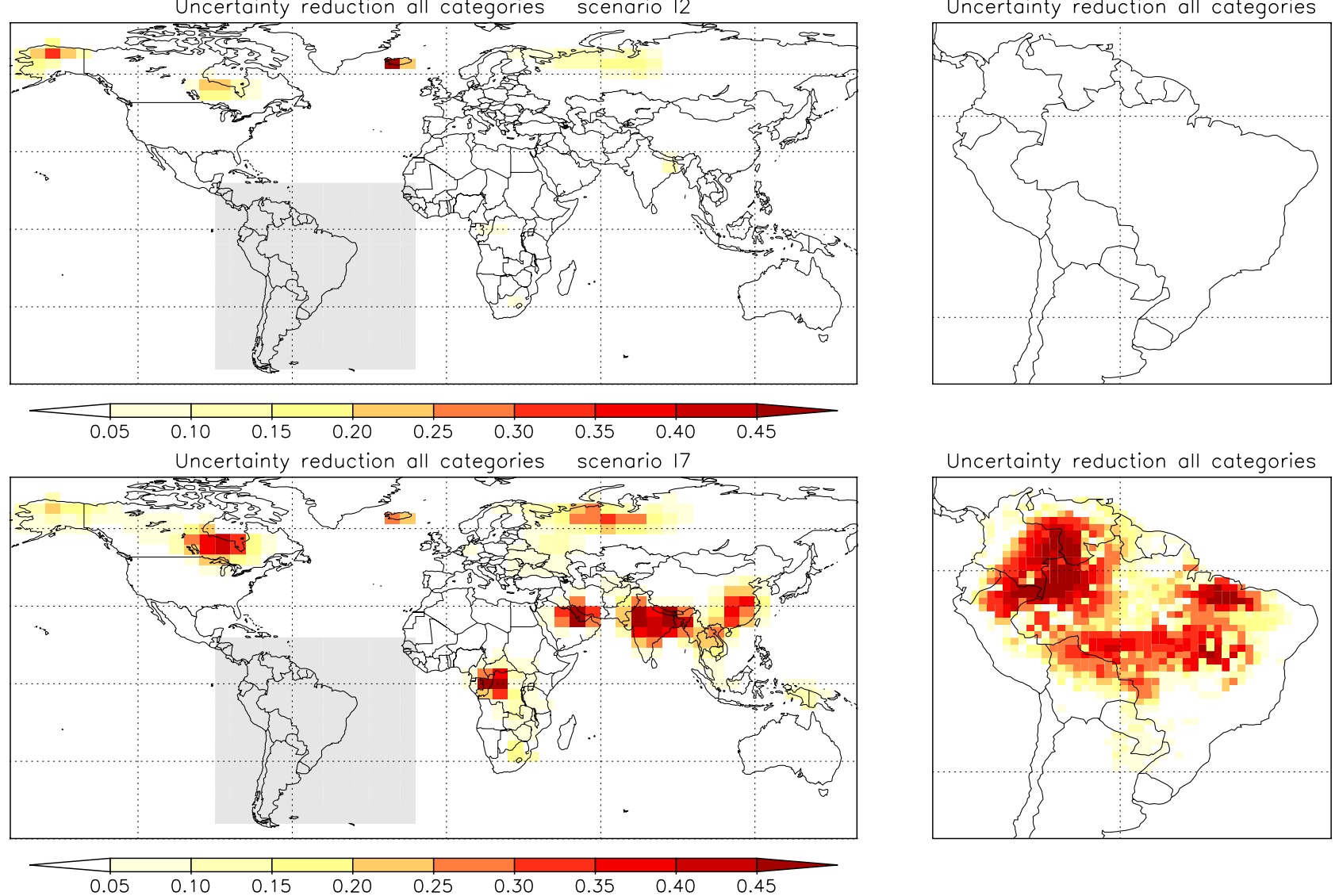

Figure 11. Uncertainty reduction for the (top) reference inversion I1, (middle) inversion I2 using only surface observations, and (bottom) inversion I7 using larger prior error correlation lengths. Uncertainty reductions have been aggregated over September to November and over all source categories. The South American zoom region has been masked in the global plots on the left and is shown in separate plots on the right.

where $\sigma_{\mathbf{y}_{i}}$ is the uncertainty of observation $\mathbf{y}_{i}$ in a subset of observations with size $n$. Substitution of $\mathbf{x}^{b}$ and $\mathbf{x}^{a}$ yields the a priori and a posteriori chi-squared, respectively. Values of $\chi^{2} / n$ with respect to surface observations and SCIAMACHY observations for a number of regions and for the different sensitivity inversions are presented in Table 3. In an optimal inversion, the a posteriori $\chi^{2} / n$, as defined in equation (2), should be somewhat smaller than 1 , depending on the contribution of the background term in the cost function to the overall chi-squared [see the discussion in Meirink et al., 2008].
[49] From Table 3 it appears that the surface observations are overall poorly reproduced by the prior model simulations. However, this poor performance is mainly related to a number of sites at high NH latitudes, where the prior wetland emissions are too high during the first part of the assimilation period. Most other stations show $\chi^{2} / n$ not far from 1 . In the posterior simulations the optimized emissions lead to a much better fit of the observations. For example, in scenario I2, with only surface observations assimilated, $\chi^{2} / n$ drops to 1.82 in the first inversion cycle. Adding SCIAMACHY observations (scenario I1) degrades $\chi^{2 / n}$ 
only slightly (to 1.99). Thus the system is able to obtain a reasonable fit to the surface observations, while also matching the SCIAMACHY observations, which would not have been possible without a satellite data bias correction. In the second inversion cycle, $\chi^{2} / n$ is further reduced because posterior outliers from the first cycle have been removed. This leads to the paradoxical result that $\chi^{2 / n}$ is lower in scenario I1 than in I2. However, this is solely due to the larger number of measurements appointed as outliers in the first cycle of scenario I1.

[50] The global posterior $\chi^{2} / n$ with respect to the SCIAMACHY observations is around 0.6. For regions with few clouds and a high surface albedo, such as the Sahara, the posterior $\chi^{2 / n}$ reaches even much lower values of around 0.2 . Thus in particular for such regions, the assumed observation error of $1.5 \%$ appears to be a clear overestimate, while elsewhere this assumption seems reasonable. However, as mentioned in section 2.2, the prior estimate of $1.5 \%$ was meant to reflect regional systematic errors rather than just random errors. In synthetic inversion experiments by Chevallier [2007] this approach to take systematic observation errors into account came out as preferable to a number of other approaches, i.e., it lead to the best correspondence between optimized and true emissions. In scenario I6 the observation error is decreased to $1.2 \%$. This leads to expected increases in $\chi^{2} / n$, and a value of twice the total posterior cost function (including background term) which exactly equals the number of observations. However, from Table 2 it is evident that this change in the assumed SCIAMACHY observation error has very little impact on the optimized emissions. A further refinement of observation error estimates will be introduced in future work but the impact on derived emissions may be limited.

[51] The other sensitivity inversions in which SCIAMACHY observations are assimilated (scenarios I3 to I5 and I7 to I10) all achieve a virtually identical posterior fit to those observations, even if the prior chi-squared varies somewhat among the scenarios. With respect to the surface observations, the prior and posterior chi-squared show more variation. The largest outlier is experiment I3, in which part of the wetland emissions have been replaced by vegetation emissions. In the prior simulation a better $\chi^{2} / n$ is obtained because part of the too-high boreal wetland emissions have been removed. In contrast, the posterior $\chi^{2} / n$ is worse, meaning that the additional prior vegetation emission pattern does not imply improved consistency with the surface observations.

[52] Two surprising features regarding the inversion without zoom over South America (scenario I9) emerge from Table 3. First, not zooming yields a lower $\chi^{2} / n$ with respect to surface observations. This, however, is an artifact of the modeling of the representativity error by the 3D-model gradient at a surface station. Two stations, RPB and ASC, are located in the zoom region, resulting in much smaller probably too small - representativity errors, and consequently larger $\chi^{2} / n$ in the reference inversion compared to the no-zoom inversion. Second, over tropical South America the no-zoom inversion yields a slightly smaller posterior $\chi^{2} / n$ with respect to SCIAMACHY than the reference inversion, whereas one would expect the loss of spatial detail to result in a larger posterior $\chi^{2} / n$. The smaller chi-squared cannot be explained by differences in the aggregated prior errors, since these were nearly identical in scenarios I1 and
19. Probably, this result indicates that the limitations for the assimilation system to fit the SCIAMACHY observations do not lie in the small-scale spatial patterns, but in the coarser scales. This hints to potential regional systematic errors in the observations or in the bottom-up emission inventories, to which prior errors are assumed to be proportional. Moreover, the relatively coarse, monthly, temporal resolution that all our inversions have in common may constitute a larger limitation to fit the observations than the spatial resolution.

\section{Comparison With Independent Airborne Observations}

[53] Miller et al. [2007] presented airborne $\mathrm{CH}_{4}$ measurements above two sites in the central Amazon, near Santarém (SAN: $2.9^{\circ} \mathrm{S}, 55.0^{\circ} \mathrm{W}$ ) and Manaus (MAN: $2.6^{\circ} \mathrm{S}, 60.0^{\circ} \mathrm{W}$ ), and a site off the Atlantic coast of Brazil, near Fortaleza (FTL: $4.1^{\circ} \mathrm{S}, 38.3^{\circ} \mathrm{W}$ ). See also Figure 1 for the location of the sites. These measurements provide excellent independent information to validate the assimilation results presented in this paper. Since we applied zooming over South America, the model should be optimally capable of resolving the local features around the measurement sites.

[54] Unfortunately, no flights were performed during the period 1 September 2003 to 10 December 2003. Therefore we collected all measurements during these months but in different years, which resulted in 12 flights ( 2 at FTL, 6 at SAN, and 4 at MAN) during the years 2000 to 2006. Model simulations based on prior emissions and posterior emissions from scenarios I1, I2, and I3 were then sampled at the same time (but different year) as the observations. To account for interannual variability in background methane, the difference between concentrations measured at the NOAA-ESRL surface station Ascension Island (ASC, see Figure 1) in the year of the observation and in 2003 was added to the simulated concentrations. This correction was small, ranging from -7.6 to $-2.2 \mathrm{ppb}$.

[55] Figure 12 shows the result of this procedure, with all flights averaged per site. FTL is dominated by trade winds from the Atlantic Ocean. The observed profiles are characterized by positive vertical gradients. This feature is nicely reproduced by the TM5 model and can be explained as follows. Methane emissions in Africa are uplifted and subsequently transported over the Atlantic, leading to elevated concentrations in the free troposphere relative to the boundary layer, in which no methane is emitted over the ocean. According to the model simulations this positive vertical gradient is strongest near the African coast, decreases over the Atlantic, but is still clearly present at the South American east coast. The prior simulation already shows good agreement with the observations, but appears to be somewhat too low. When only surface observations are assimilated (experiment I2), higher concentrations are modeled as a consequence of generally increased emissions in the tropics. This effect is even stronger when SCIAMACHY observations are added (experiment I1). Both inversions I1 and I2 show a similarly improved agreement with the observations compared to the prior simulation.

[56] At $\mathrm{SAN}$, observed $\mathrm{CH}_{4}$ concentrations range from about $1770 \mathrm{ppb}$ at $4 \mathrm{~km}$ altitude to almost $1850 \mathrm{ppb}$ on average near the surface. The a priori simulation underestimates the observations at all levels but mostly near the 


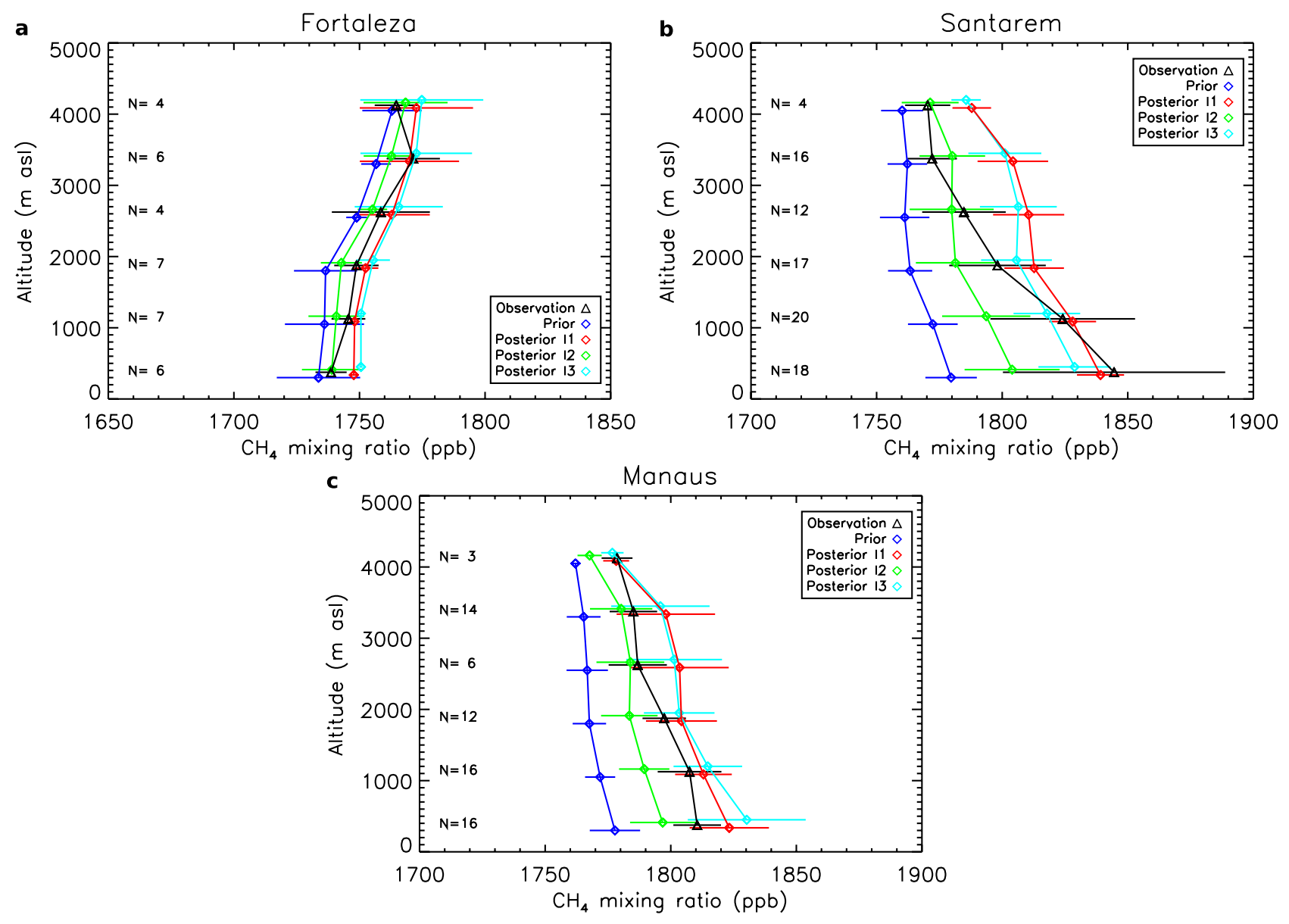

Figure 12. Comparison of (diamonds) model simulations with (triangles) aircraft observations [Miller et al., 2007] at three sites in Brazil: (a) Fortaleza, (b) Santarém, and (c) Manaus. Four different model simulations are shown: based on prior emissions (blue), and based on posterior emissions from (red) reference scenario I1, (green) from scenario I2 with only surface observations assimilated, and (pale blue) from scenario I3 with prior vegetation emissions replacing part of the wetland emissions. Observations and model concentrations have been binned in 750-m vertical bins. Symbols show the mean, and horizontal bars show the standard deviation of the observed/modeled concentrations in a bin. The symbols and bars have been slightly vertically offset with respect to each other for clarity. The number of observations in each height bin is given in the plots. The modeled concentrations have been corrected for interannual variability as described in the text.

surface, where the difference is about $65 \mathrm{ppb}$. This indicates that there are considerable regional methane sources which are not present in the a priori inventories. When surface observations are assimilated (scenario I2), modeled concentrations increase, fitting the measurements very well above $2 \mathrm{~km}$, but still underestimating them at lower levels. This situation is reversed when SCIAMACHY observations are also assimilated (scenario I1). In this case, the observed near-surface enhancements are accurately reproduced (on average), but above $2 \mathrm{~km}$ the model overestimates the observations by 20 to $30 \mathrm{ppb}$.

[57] At MAN, the measured concentrations decrease with height, as at SAN, but the vertical gradient is much smaller, suggesting less influence from nearby sources. Again, the prior simulation underestimates the observations at all levels. When surface observations are assimilated, the modeled concentrations increase but are still too low. On the other hand, when SCIAMACHY observations are added, the model simulates too-high concentrations. Both at SAN and at MAN, scenarios I1 and I2 agree about equally well with the observations.

[58] Obviously, the number of profiles analyzed here is limited. Furthermore, the influence of the particular meteorological situation at the time of the measurements - with winds either or not blowing from emission regions - is not taken into account, since the model simulations are for a different year than the observations. Therefore we also conducted a two-year (2003 and 2004) inversion, without zoom to keep reasonable computational costs. Despite the longer time window, now covering all seasons, the availability of more profiles, and the correspondence between observation and model dates, the comparison between model simulations and observations showed qualitatively the same picture as in Figure 12.

[59] As mentioned before, the observed vertical gradient at SAN is much larger than at MAN. This suggests that there are substantial methane emissions just east of SAN, where the wind is mainly coming from. Near the MAN site, 
which is located $\approx 600 \mathrm{~km}$ downwind, the methane profile appears to have been flattened considerably by vertical mixing in combination with limited additional emissions at the surface. The failure of the model to reproduce the difference between observed vertical profiles at the two Amazonian sites may have various causes. For example, modeled vertical mixing might be too fast, resulting in tooflat vertical profiles at SAN. There is also limited coverage of the region around SAN and MAN by SCIAMACHY (see Figure 5), reducing the probability that strong emission events are picked up. Finally, the bottom-up spatial emission distributions, to which prior errors are assumed to be proportional, may be wrong, thus preventing emissions to be added at the right locations. In scenario I3, part of the wetland emissions were replaced by vegetation emissions, leading to a different, more homogeneous prior emission distribution over tropical South America. This scenario leads to a slightly worse agreement between simulated and observed vertical gradients (Figure 12). It thus appears that vegetation emissions, in the way they are included in the model here, cannot explain the specific differences between the SAN and MAN sites.

[60] Analysis of the individual profiles reveals a large temporal variability, in particular at the lower altitudes at SAN (not shown). While the average $\mathrm{CH}_{4}$ concentration measured there is accurately reproduced using SCIAMACHY-based optimized emissions, the individual profiles are often significantly over- or underestimated, even by the 2-year inversion in which the model was sampled at the exact time of the observations. This suggests that there is considerable temporal variability in emission rates, which cannot be resolved by our monthly-mean fluxes.

[61] Above $2 \mathrm{~km}$ altitude, the assimilation of SCIAMACHY observations leads to too-high methane concentrations compared with the airborne observations at both SAN and MAN. The measurements at these heights resemble emissions in a reasonably large footprint around (actually, due to the prevailing trade winds, mainly east of) the sites. We may thus conclude that the estimated emission rates in eastern tropical South America are generally too high. This in turn suggests that the SCIAMACHY observations may have some regional bias, in addition to the average latitudinal bias correction already applied in the inversion. Such a regional bias could, for example, be related to aerosols (both amount and type), surface properties or clouds (see Bergamaschi et al. [2007] for a discussion). It is very difficult to correct for unknown regional biases, and trying to do so brings with it the risk that actual emission signals are falsely designated as retrieval biases. This could for example be the case if an aerosol bias correction were introduced, since a process like biomass burning emits both aerosols and methane. At the same time, the potential presence of unaccounted regional biases in the satellite observations inevitably causes a significant uncertainty in derived flux estimates.

\section{Conclusions}

[62] An inverse modeling study of atmospheric methane emissions using SCIAMACHY satellite observations and NOAA-ESRL surface observations has been conducted with a 4D-Var assimilation system developed in Meirink et al. [2008]. The focus is on September through November 2003, during which SCIAMACHY observed high $\mathrm{CH}_{4}$ concentrations in the tropics, particularly in South America [Frankenberg et al., 2005]. Therefore this continent is modeled at high $\left(1^{\circ} \times 1^{\circ}\right)$ spatial resolution, exploiting the zooming capability of the TM5 atmospheric transport model.

[63] It is shown that, after assimilation, good agreement is obtained between model and observations, both from SCIAMACHY and from the surface network. However, a prerequisite for achieving this consistency with both types of observations is the application of a bias correction to the satellite observations. Here, we followed the approach of Bergamaschi et al. [2007], estimating a monthly latitudedependent bias in the SCIAMACHY observations, which appears to work fairly well, although some aliasing with the jointly estimated emission rates is to be expected.

[64] The main emission increments resulting from the inversion are an increase in the tropics, a decrease in South Asia, and a decrease at northern hemispheric high latitudes. The tropical and South-Asian increments are mainly imposed by SCIAMACHY observations, whereas the $\mathrm{NH}$ high-latitude emissions are mainly constrained by the surface network. The South-Asian emission reduction, attributed to rice cultivation, is very specific to the time period chosen in our inversion. Over a whole year, SCIAMACHY observations do not suggest large reductions in rice cultivation emissions [Bergamaschi et al., 2007].

[65] Our 4D-Var implementation allows the estimation of uncertainties in the posterior emission estimates. The assimilation of SCIAMACHY observations yields aggregated uncertainty reductions of $60-80 \%$ over tropical South America, tropical Africa and South Asia, compared to $20-30 \%$ when only surface observations are used. In the extratropical northern hemisphere the added value of SCIAMACHY is much lower because this part of the globe is much better constrained by the surface network.

[66] Statistics of the differences between observations and optimized model simulations have been used to give an indication of upper bounds to the observation errors. For regions with a high surface albedo, such as the Sahara desert, the precision of daily- and $1^{\circ} \times 1^{\circ}$-averaged SCIAMACHY observations is estimated to be about $0.7 \%$, which translates to approximately $1 \%$ for individual observations. Over darker surfaces, such as tropical rain forests, the estimate of individual observation precision is typically $1.8 \%$.

[67] For tropical South America, the inversion suggests more than a doubling of emissions compared to the a priori. This result remains unchanged in an extensive series of sensitivity experiments, and thus appears to be a robust feature following from the SCIAMACHY observations.

[68] Another interesting result emerging from the sensitivity experiments is that an inversion without zooming achieves an equally good fit to the satellite observations as the reference inversion. This indicates that the limitations for the assimilation system to fit the SCIAMACHY observations do not lie in the small-scale spatial patterns, but in the coarser scales. This in turn hints to potential regional systematic errors in the observations or in the bottom-up emission inventories, and also suggests that the relatively 
coarse, monthly, temporal resolution of our inversions may constitute a larger limitation to fit the observations than the spatial resolution.

[69] The high spatial resolution does, however, allow for a detailed comparison with independent airborne measurements near Santarém (SAN) and Manaus (MAN) in the Amazon, and Fortaleza (FTL) at the Brazilian east coast [Miller et al., 2007]. Whereas the prior model simulation underestimates methane at all three sites, the inversions using only surface observations or both surface and SCIAMACHY observations lead to higher concentrations and a much better correspondence with the airborne measurements. At SAN, strong vertical gradients are measured, suggesting the presence of nearby upwind sources. In contrast, the measurements at MAN, located approximately $600 \mathrm{~km}$ to the west, show much flatter vertical profiles, suggesting that methane has been vertically mixed during westward transport, while relatively limited further emissions have been added. This particular difference between vertical profiles at SAN and MAN is not reproduced by the model in prior mode, nor in assimilation mode. The introduction of vegetation emissions as recently proposed by Keppler et al. [2006] does also not resolve this conflict. The discrepancy between modeled and observed vertical profiles at the two Amazonian sites may be due to a variety of reasons, including errors in modeled vertical mixing, limited coverage of the region by SCIAMACHY observations, and errors in the spatio-temporal prior emission distributions.

[70] Analysis of the airborne observations above $\approx 2-\mathrm{km}$ altitude reveals that the assimilation of SCIAMACHY observations causes a general overestimate of methane concentrations at both Amazonian sites. This suggests that the SCIAMACHY observations in eastern South America, and perhaps also in other parts of the tropics, may have a positive bias in addition to the average latitude-dependent bias estimated in the inversion. Further work is needed to detect and repair potential biases in the retrieval process as any regional patterns in the bias that are identified may lead to shifts in the overall distribution of emission estimates.

[71] Acknowledgments. Jan Fokke Meirink was supported by the NWO project IMEAS (project EO-087). Peter Bergamaschi was supported by the European Commission RTD project GEMS (Global and regional Earth-system (atmosphere) monitoring using satellite and in-situ data), contract SIP4-CT-2004-516099, 6th Framework Programme. Computer facilities were provided by the Dutch NCF (Nationale Computerfaciliteiten). We thank NOAA-ESRL for providing CarbonTracker data. SAN and MAN air samples were collected as part of the Brazilian-led large-scale biosphere-atmosphere experiment in Amazonia (LBA), and funded from NASA interagency agreements S-10137 and S-71307.

\section{References}

Bergamaschi, P., M. Krol, F. Dentener, A. Vermeulen, F. Meinhardt, R. Graul, M. Ramonet, W. Peters, and E. J. Dlugokencky (2005), Inverse modelling of national and European $\mathrm{CH}_{4}$ emissions using the atmospheric zoom model TM5, Atmos. Chem. Phys., 5, 2431-2460.

Bergamaschi, P., et al. (2007), Satellite chartography of atmospheric methane from SCIAMACHY on board ENVISAT: 2. Evaluation based on inverse model simulations, J. Geophys. Res., 112, D02304, doi:10.1029/2006JD007268

Bousquet, P., et al. (2006), Contribution of anthropogenic and natural sources to atmospheric methane variability, Nature, 443, 439-443, doi:10.1038/nature05132.

Buchwitz, M., et al. (2005), Atmospheric methane and carbon dioxide from SCIAMACHY satellite data: Initial comparison with chemistry and transport models, Atmos. Chem. Phys., 5, 941-962.
Buchwitz, M., et al. (2006), Atmospheric carbon gases retrieved from SCIAMACHY by WFM-DOAS: Version 0.5 . $\mathrm{CO}$ and $\mathrm{CH}_{4}$ and impact of calibration improvements on $\mathrm{CO}_{2}$ retrieval, Atmos. Chem. Phys., 6, $2727-2751$.

Chen, Y.-H., and R. G. Prinn (2006), Estimation of atmospheric methane emissions between 1996 and 2001 using a three-dimensional global chemical transport model, J. Geophys. Res., 111, D10307, doi:10.1029/ 2005JD006058.

Chevallier, F. (2007), Impact of correlated observation errors on inverted $\mathrm{CO}_{2}$ surface fluxes from OCO measurements, Geophys. Res. Lett., 34, L24804, doi:10.1029/2007GL030463.

Dlugokencky, E. J., L. P. Steele, P. M. Lang, and K. A. Masarie (1994), The growth rate and distribution of atmospheric methane, J. Geophys. Res., 99(D8), 17,021-17,043.

Dlugokencky, E. J., R. C. Myers, P. M. Lang, K. A. Masarie, A. M. Crotwell, K. W. Thoning, B. D. Hall, J. W. Elkins, and L. P. Steele (2005), Conversion of NOAA atmospheric dry air $\mathrm{CH}_{4}$ mole fractions to a gravimetrically prepared standard scale, J. Geophys. Res., 110, D18306, doi:10.1029/2005JD006035.

Dlugokencky, E. J., S. Houweling, L. Bruhwiler, K. A. Masarie, P. M. Lang, J. B. Miller, and P. P. Tans (2003), Atmospheric methane levels off: Temporary pause or a new steady-state?, Geophys. Res. Lett., 30(19), 1992, doi:10.1029/2003GL018126.

Dueck, T. A., et al. (2007), No evidence for substantial aerobic methane emissions by terrestrial plants: A ${ }^{13} \mathrm{C}$-labelling approach, New Phytol., $175,29-35$.

Etheridge, D. M., G. I. Pearman, and P. J. Fraser (1992), Changes in tropospheric methane between 1841 and 1978 from a high accumulation-rate Antarctic ice core, Tellus, 44B, 282-294.

Fisher, M., and P. Courtier (1995), Estimating the covariance matrices of analysis and forecast error in variational data assimilation, Tech. Mem. 220, ECMWF, Reading, U.K.

Frankenberg, C., J. F. Meirink, M. van Weele, U. Platt, and T. Wagner (2005), Assessing methane emissions from global space-borne observations, Science, 308(5724), 1010-1014.

Frankenberg, C., J. F. Meirink, P. Bergamaschi, A. P. H. Goede, M. Heimann, S. Körner, U. Platt, M. van Weele, and T. Wagner (2006), Satellite chartography of atmospheric methane from SCIAMACHY on board ENVISAT: Analysis of the years 2003 and 2004, J. Geophys. Res., 111, D07303, doi:10.1029/2005JD006235.

Heimann, M., and S. Körner (2003), The global atmospheric tracer model TM3: Model description and users manual release 3.8a, Tech. Rep. 5, Max Planck Inst. for Biogeochem. (MPI-BGC), Jena, Germany.

Hein, R., P. J. Crutzen, and M. Heimann (1997), An inverse modelling approach to investigate the global atmospheric methane cycle, Global Biogeochem. Cycles, 11(1), 43-76.

Houweling, S., T. Kaminski, F. J. Dentener, J. Lelieveld, and M. Heimann (1999), Inverse modelling of methane sources and sinks using the adjoint of a global transport model, J. Geophys. Res., 104(D21), 26,137-26,160.

Houweling, S., T. Röckmann, I. Aben, F. Keppler, M. Krol, J. F. Meirink, E. J. Dlugokencky, and C. Frankenberg (2006), Atmospheric constraints on global emissions of methane from plants, Geophys. Res. Lett., 33, L15821, doi:10.1029/2006GL026162.

Keppler, F., J. T. G. Hamilton, M. Brass, and T. Röckmann (2006), Methane emissions from terrestrial plants under aerobic conditions, Nature, 439, 187-191, doi:10.1038/nature04420.

Krol, M., S. Houweling, B. Bregman, M. van den Broek, A. Segers, P. van Velthoven, W. Peters, F. Dentener, and P. Bergamaschi (2005), The twoway nested global chemistry-transport zoom model TM5: Algorithm and applications, Atmos. Chem. Phys., 5, 417-432.

Meirink, J. F., H. J. Eskes, and A. P. H. Goede (2006), Sensitivity analysis of methane emissions derived from SCIAMACHY observations through inverse modelling, Atmos. Chem. Phys., 6, 1275-1292.

Meirink, J. F., P. Bergamaschi, and M. C. Krol (2008), Four-dimensional variational data assimilation for inverse modelling of atmospheric methane emissions: Method and comparison with synthesis inversion, Atmos. Chem. Phys. Disc., 8, 12,023-12,052.

Mikaloff Fletcher, S. E. M., P. P. Tans, L. M. Bruhwiler, J. B. Miller, and M. Heimann (2004), $\mathrm{CH}_{4}$ sources estimated from atmospheric observations of $\mathrm{CH}_{4}$ and its ${ }^{13} \mathrm{C} /{ }^{12} \mathrm{C}$ isotopic ratios: 1. Inverse modeling of source processes, Global Biogeochem. Cycles, 18, GB4004, doi:10.1029/2004GB002223.

Miller, J. B., L. V. Gatti, M. T. S. d'Amelio, A. M. Crotwell, E. J. Dlugokencky, P. Bakwin, P. Artaxo, and P. P. Tans (2007), Airborne measurements indicate large methane emissions from the eastern Amazon basin, Geophys. Res. Lett., 34, L10809, doi:10.1029/ 2006 GL029213.

Peters, W., et al. (2007), An atmospheric perspective on North American carbon dioxide exchange: Carbon Tracker, Proc. Natl. Acad. Sci. USA. $104,18,925-18,930$. 
Spivakovsky, C. M., et al. (2000), Three-dimensional climatological distribution of tropospheric $\mathrm{OH}$ : Update and evaluation, J. Geophys. Res., 105(D7), $8931-8980$.

P. Bergamaschi and M. G. Villani, European Commission DG Joint Research Centre, IES CCU, TP 263, Via Fermi, I-21020 Ispra (VA), Italy. (peter.bergamaschi@jrc.it; maria-gabriella.villani@jrc.it)

M. T. S. d'Amelio and L. V. Gatti, Instituto de Pesquisas Energéticas e Nucleares, Av. Lineu Pretes 2242, 05508-900, São Paulo, SP, Brazil. (lvgatti@net.ipen.br)

E. J. Dlugokencky and J. B. Miller, NOAA Earth System Research Laboratory, 325 Broadway, Boulder, CO 80305, USA. (ed.dlugokencky@ noaa.gov; john.b.miller@noaa.gov)
C. Frankenberg and S. Houweling, Netherlands Institute for Space Research, Sorbonnelaan 2, 3584 CA, Utrecht, Netherlands. (c.frankenberg@ sron.nl; s.houweling@sron.nl)

M. C. Krol, Wageningen University and Research Centre, P.O. Box 47, 6700 AA, Wageningen, Netherlands. (m.c.krol@phys.uu.nl)

J. F. Meirink, Climate Observations Department, Royal Netherlands Meteorological Institute, P.O. Box 201, 3730 AE, De Bilt, Netherlands. (meirink@knmi.nl)

T. Röckmann, Institute for Marine and Atmospheric Research Utrecht, University of Utrecht, P.O. Box 80005, 3508 TA, Utrecht, Netherlands. (t.roeckmann@phys.uu.nl) 